Research Article

\title{
The Stress Calculation Methods of Antislide Structures with Continuous Ladders
}

\author{
Gong Chen $(\mathbb{D})$ and Qiang Xu \\ State Key Laboratory of Geohazard Prevention and Geoenvironment Protection, Chengdu University of Technology, \\ Chengdu 610059, Sichuan, China \\ Correspondence should be addressed to Gong Chen; 13880680121@139.com
}

Received 8 September 2020; Revised 9 November 2020; Accepted 7 December 2020; Published 21 December 2020

Academic Editor: Hui Yao

Copyright $\odot 2020$ Gong Chen and Qiang Xu. This is an open access article distributed under the Creative Commons Attribution License, which permits unrestricted use, distribution, and reproduction in any medium, provided the original work is properly cited.

\begin{abstract}
In antislide structures with continuous ladders (ASCLs), horizontal and vertical reinforced concrete antislide members connected in continuous ladders, head to tail, are set along the slip surfaces of slopes. The antislide members are connected with each other and anchored in the solid bedrock from the sliding mass to the sliding zone to resist the landslide thrust and replace the soft materials in the sliding zone. The effects of ASCLs, which are complex and hyperstatic mechanical systems, are calculated by using different numerical simulation software programs and compared with engineering practice experience. However, these effects are uncertain and the use of other analysis methods is required to verify them. In this paper, first, the antislide mechanism of these structures was proposed. Second, the slip surfaces were taken as boundaries, and the ASCL of the Houzishi landslides was taken as an example. Third, the stress models of the structures and load effects were simplified, and then, an ASCL stress calculation method was established to obtain the expressions for structural stress analysis by using the displacement method of structural mechanics, elastic foundation beam method, and boundary constraints. A comparison of the results of the structural stress from the analytical methods and numerical simulation methods indicated that the whole displacement of the structures exhibited a domino effect, which was downwards to the right. The trends of the structural stress determined with the analytical methods and numerical simulation methods were similar. The ultimate results of the analytical methods and the ultimate results of the numerical simulation methods were also similar. The conclusions proposed that the ultimate results of the analytical methods exhibited a hysteretic effect, unlike the ultimate results of the numerical simulation methods. The ultimate results of the analytical methods and numerical simulation methods were adopted for the design of structural stress based on the principle of internal stress envelope diagrams.
\end{abstract}

\section{Introduction}

1.1. Summary of the Structures. Antislide structures with continuous ladders (ASCLs) are complex and hyperstatic mechanical systems. The horizontal and vertical reinforced concrete antislide members connected in continuous ladders, head to tail, are set along the slip surface of a slope. The antislide members are connected with each other and anchored in the solid bedrock from the sliding mass to the sliding zone to resist the landslide thrust and replace the soft materials in the sliding zone [1].

The longitudinal profile of one ASCL along the slip surface of a slope is shown in Figure 1. Many ASCLs are connected by using horizontal binding beams that are similar to the binding beams in the frame structures to increase the global stability and antisliding capacity. The plane layout of an ASCL is shown in Figure 2 [1]. Due to the horizontal and vertical reinforced concrete antislide members that are connected in head to tail continuous ladders and the slip surface that the ASCLs pass through at a large depth, the construction technology of ASCLs is different from other traditional antislide structures. First, the vertical guidance holes are excavated. Second, the horizontal major holes (horizontal binding beams) are excavated. Third, the horizontal holes (horizontal reinforced concrete antislide members) are excavated alternately from both ends of the 


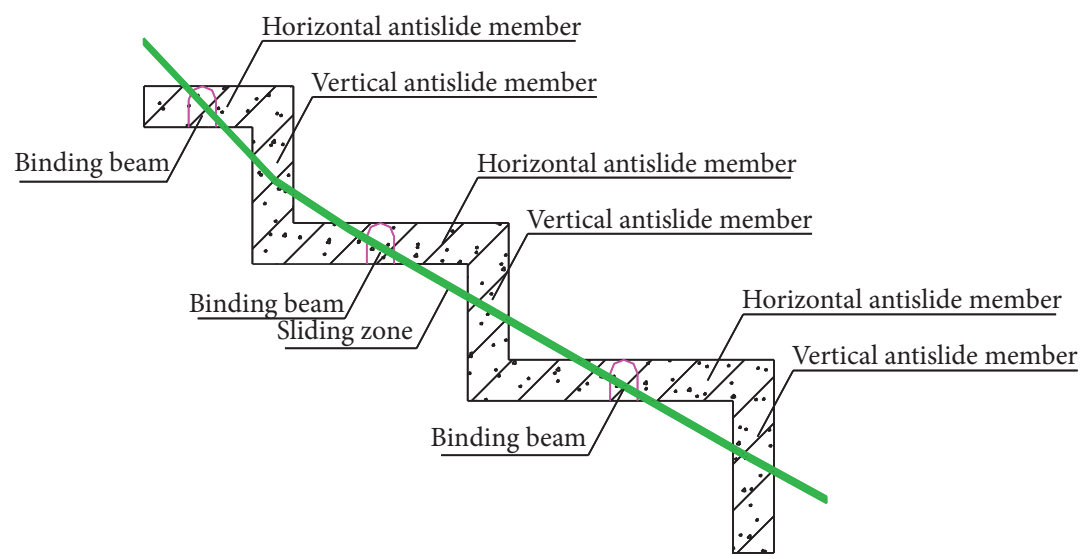

FIgURE 1: The longitudinal profile of one ASCL along the slip surface of a slope. The zone above the sliding zone is a sliding body while the zone below the sliding zone is a slip bed. Binding beams connect the ASCLs along the horizontal direction.

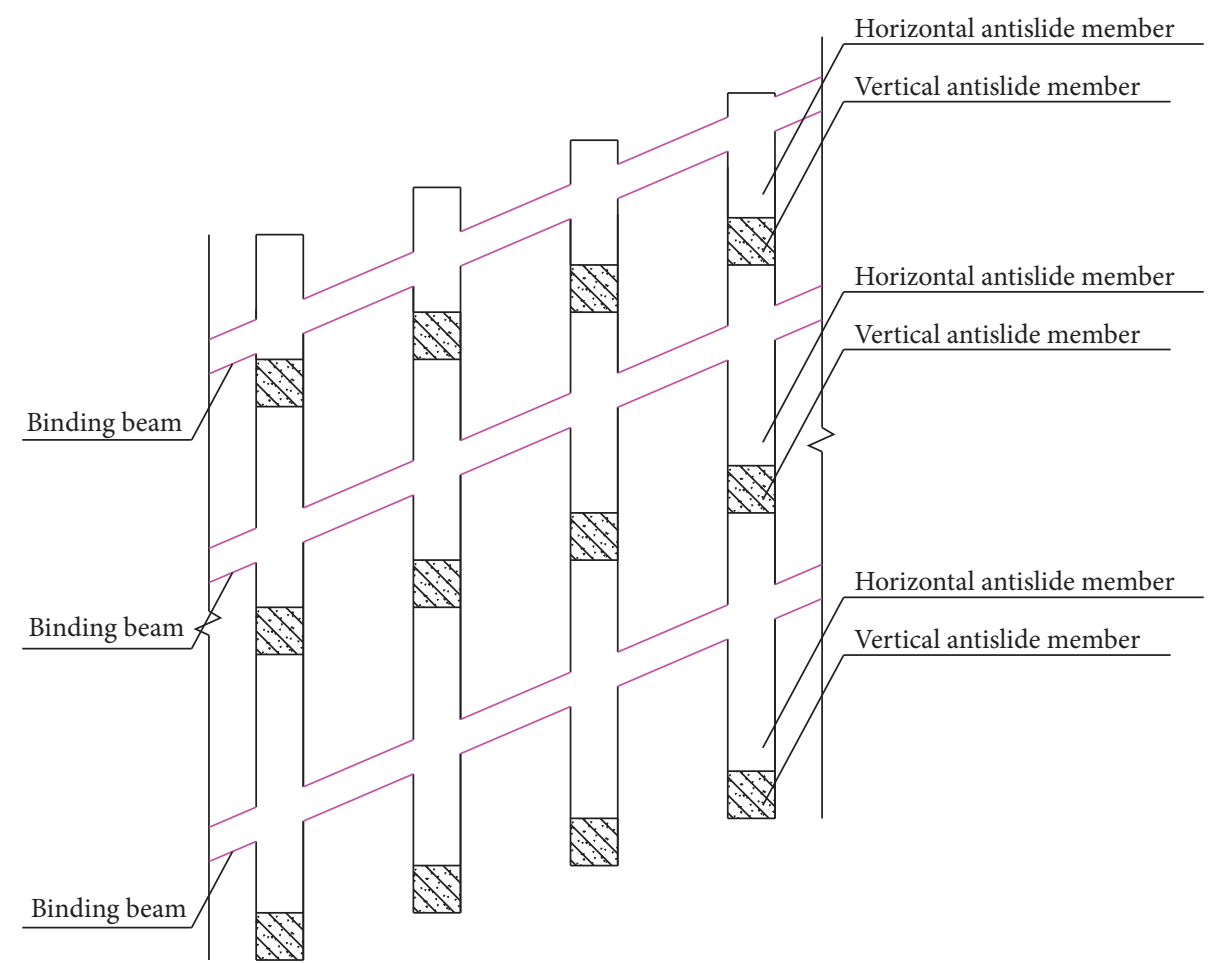

FIgURE 2: The plane layout of an ASCL. ASCLs are constructed along the longitudinal direction. Binding beams connect the ASCLs along the horizontal direction.

horizontal major holes. Finally, the vertical holes (vertical reinforced concrete antislide members) are excavated at the end of the horizontal holes; in addition, the horizontal and vertical reinforced concrete antislide members are gradually constructed [2].

ASCLs are applicable to landslides where the rock masses above and below a slip surfaces are integrated, the structures in the sliding bodies are small, the positions of the slip surfaces are clear and deep, and the landslide thrust is large. The global stability of the rock is enhanced by strengthening the mechanical properties of the geotechnical materials applied in the sliding zone or around it. ASCLs have been successfully used in the Houzishi landslides in Fengjie
County of Chongqing city, as the most complex geohazard governance in the Three Gorges Reservoir Area in terms of sequential bedrock landslides [2].

1.2. Literature Review. Zou et al. [3] simulated and calculated the antisliding effects and structural stress of an ASCL by using Fast Lagrangian Analysis of Continua (FLAC) software. The research showed that the safety and stability of landslides increase and that good geohazard governance could be obtained by using an ASCL. Fu et al. [4] researched the landslide stabilization effects of an ASCL, which were simulated and calculated by using the finite difference 
strength reduction method, according to the design and construction of a landslide treatment. Ma [5] used FLAC to simulate and calculate the axial force, the shear force, and the bending moment of an ASCL. The research showed that not only the stress state of the ASCL met the design requirements but also the safety and stability of landslides were improved. Zheng [1] concluded that axial force, shear force, and bending moment are borne by an ASCL and that the deformation of an ASCL is smaller when antislide piles are also implemented by using FLAC to compare stress and the deformation results. In addition, Zheng and Hong [2] proposed that the internal antislide mechanism of an ASCL effectively decreased the shearing deformation of the sliding zone, the development of the plastic zone, and the global displacement of the sliding body and effectively increased the resistance of the geotechnical materials; additionally, they identified that the external antislide mechanism of an ASCL improved the mechanical properties of the geotechnical materials and developed a global antislide function by using FLAC to simulate and calculate the effects of the ASCL on landsliding.

Based on the assumption of ideal elastic-plastic material, Ito and Matsui [6] obtained the relation between the strength parameters and the sliding resistance force provided by the single antislide pile. Rajashree and Sundaravedivelu [7] carried out the analysis of laterally loaded piles in soft clay, idealising the pile as beam elements and the soil by nonlinear inelastic spring elements modelled with elastoplastic subelements. Halabe and Jaina [8] analysed the single piles under pure lateral loads and discussed the influence of related parameters. Hassiotis et al. [9] proposed a methodology for the design of slopes reinforced with a single row of piles. Abbas et al. [10] carried out the deformation behavior of piles was related to the section shape and slenderness ratio of piles. Frank and Pouget [11] proposed the excavation or increases in the driving force of landslides behind piles led to the deformation of piles and even pile damage. Kourkoulis et al. [12] used a hybrid method for the analysis and design of slope-stabilizing piles. Nian et al. [13] performed 3D numerical analysis for typical examples of slopes reinforced with antislide piles using the strength reduction FEM with consideration of the interaction of the pile, soil, and slope. In landslide controlling, Lirer [14] proposed the antislide piles played an important role and coordinate deformation with the surrounding soil to improve the stability of the whole slope. Ashour and Ardalan [15] presented a new procedure for the analysis of slope stabilization using piles. Shooshpasha and Amirdehi [16] studied the stability analysis of slopes reinforced with one row of free head piles by using the shear strength reduction method with the software of Abaqus. Tehrani et al. [17] proposed the calculation of pile displacement was achieved under certain loads. Kahyaoglu et al. [18] proposed the equation of pile deformation, as proposed under different lateral load patterns, was related to the elastic modulus and moment of inertia of the pile; the cantilever pile length affected the distributions of slope pressure above the slip surface. Vega-Posada Carlos et al. [19] developed a simplified analytical approach to analyze soil-structure interaction of beam-column elements (i.e., beams, columns, and piles) with generalized end-boundary conditions on a homogeneous or nonhomogeneous Pasternak foundation. Aqoub et al. [20] proposed that the transfer of loads to the piles was increased during the monotonic loading stage but at a lower rate with increasing the embankment height. Belato et al. [21] researched on the performance of semiempirical methods based on the standard penetration test (SPT) for the prediction of bearing capacity already disseminated in the practice of Brazilian Foundation Engineering. Pratap and Chatterjee [22] observed that the maximum bending moment increased and more mobilization of earth pressure taken place with increase in horizontal seismic acceleration coefficients, magnitude of uniform surcharge, and embedded depth and decrease in the distance of surcharge from the top of the wall in loose sand. Naphol et al. [23] researched an experimental investigation of the properties of CFG. Fattah et al. [24] presented a series of model experiments conducted on single pile embedded in saturated and unsaturated expansive soil. Amir et al. [25] researched that the group reduction factor was considered as a parameter commonly used in spring models created from pile groups to consider the group effects in soil-pile interaction analysis.

1.3. Research Significance. The effects of ASCLs, which are complex and hyperstatic mechanical systems, are calculated and contrasted by using different numerical simulation software or engineering practice experience. However, these effects remain uncertain, and the use of other analysis methods is required to verify them. There has been no research on the stress calculation methods for ASCLs in the relevant codes, professional books, or research literature in China, such as the Design code for geohazard prevention (DB 50/5029-2004) [26], Specification of design and construction for landslide stabilization (DZ/T 0219-2006) [27], Design code for engineered slopes in hydropower projects and water resources (DL/T 5353-2006) [28], Design code for engineered slopes in water resources and hydropower projects (SL 386-2007) [29], and Engineering design and examples of the new type of supporting structures [30]. Applied research on ASCLs has been performed on the construction plan, construction technology, numerical simulation, monitoring, etc., but basic research on ASCLs is lacking.

Based on the above research background, scientific references are provided not only for the specifications and structural design of an ASCL but also to fill the gaps in the basic research of these structures, starting with the antislide mechanism and the stress calculation method of ASCLs.

\section{Theoretical Models}

2.1. Antislide Mechanism of an ASCL. Assuming a slip surface as a boundary in the ASCL, the resultant force due to the thrust, which is distributed to the horizontal and vertical antislide members above the slip surfaces, and the sliding resistance in front of the antislide members, which can resist 
part of the landslide thrust, impact the horizontal and vertical antislide members above the slip surfaces: these forces include the axial force, the shear force, and the bending moment. Due to the connections of the antislide members, the effects on the slip surfaces are transmitted to the solid bedrock by the anchoring effects between the antislide members below the slip surfaces and the slip bed.

2.2. Basic Ideas. Above the slip bed, which consists of solid bedrock, the sliding body may slide along a slip surface of the slope. Assuming a slip surface is a boundary in the ASCL, the horizontal and vertical antislide members above the slip surfaces are simplified to be the nonstatic structures that are fastened on the slip surfaces, so the resultant force due to the thrust and the sliding resistance in front of the antislide members are simplified to be the external load; therefore, the structures above the slip surfaces can be analysed by using the displacement method of structural mechanics.

Compared with the slip bed, which is simplified to be the foundation, the internal stress of the horizontal and vertical antislide members below the slip surfaces, which are embedded in the slip bed and simplified to be the structures in the foundation, can be calculated and analysed by using elastic foundation beam methods.

2.3. Simplification of the Mechanical Model. According to the mechanical design and construction technology of an ASCL, the combination of the horizontal and vertical antislide members are simplified to be rigid frames due to the connection nodes, which are simplified as rigid nodes. As mentioned before, the effects of the ASCL, which are complex and hyperstatic mechanical systems, are difficult to calculate and analyze. Taking the shape of the ASCL of the Houzishi landslides as an example, the three-dimensional (3D) structures are simplified to be two-dimensional (2D) structures, which are taken as one ASCL in the landslides. This ASCL is shown in Figure 3.

2.4. Simplification of the Load. If a sliding body contains a complete rigid layer, nondisturbed stiff clay, or similar rock-like material, the landslide thrust is assumed to have a rectangular distribution. If a sliding body contains gravelly soil or rocky soil, the landslide thrust is assumed to have a triangular distribution. If a sliding body contains materials with geotechnical properties between those of the abovementioned materials, the landslide thrust is assumed to have a trapezoidal distribution, which can be represented as the superimposition of a rectangular distribution and a triangular distribution. While the sliding bodies in front of the structures and above the slip surfaces may slide, hypothetically, the upper part of the structures does not bear the resistance. However, while the sliding bodies in front of the structures and above the slip surfaces are fundamentally stable, the upper part of the structures bears the resistance, which is assumed to be equal to or less than the excess sliding force and the passive earth pressure of the slip bodies in front of the structures, as the resistance in front of the structures is assumed to be equal to the

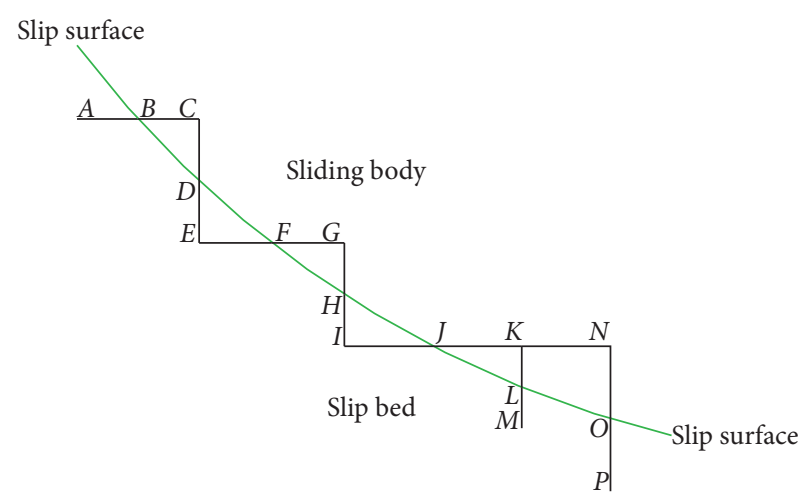

FIgure 3: One ASCL in a landslide. The zone above the sliding zone is a sliding body while the zone below the sliding zone is a slip bed. Assuming a slip surface as a boundary in the ASCL, the ASCL is disintegrated into the section above the slip surface and the section below the slip surface. The ends of the antislide members and the intersection on the slip surface are numbered in English letters.

minimum of the excess sliding force and the passive earth pressure of the slip bodies in front of the structures. In structural design, the resistance distribution of the structures is usually adopted to match the landslide thrust distribution or a parabolic curve. The bearing load of the structures above the slip surfaces is controlled by the landslide thrust and the resistance in front of the structures, and the distribution type is usually rectangular, triangular, or trapezoidal [31].

The major loads on the ASCL are due to the landslide thrust, the resistance in front of the structures, and the anchoring effects between the antislide members and the slip bed, while the minor loads on the ASCL are due to the gravity of the antislide members, the friction and endbearing forces of the antislide members, and geotechnical factors. When the structural stress is calculated and analysed, the minor loads and the axial deformation of the structures should be neglected due to the short length of the horizontal and vertical antislide members. As mentioned before, the ASCL is applicable to landslides where the rock masses above and below a slip surface are integrated, the structures in the sliding bodies are small, the positions of the slip surfaces are clear and deep, and the foundation coefficient above the slip surfaces changes minimally. The resultant force due to the thrust and the sliding resistance in front of the antislide members is simplified to be a trapezoidal load distributed across the antislide members above the slip surface, which can be decomposed into a rectangular load and a triangular load. The trapezoidal load near the slip surfaces is strong, whereas the trapezoidal load far from the slip surfaces is weak. The simplified figure of the load effects of the ASCL above the slip surfaces is shown in Figure 4.

2.5. Boundary Conditions below the Slip Surfaces. The section size and partitioned length above and below the slip surfaces, which should be equal or approximately equal, are relevant to the geological conditions, the location of the structures, etc. The horizontal and vertical antislide members may be partly rigid members or partly elastic members due to the 


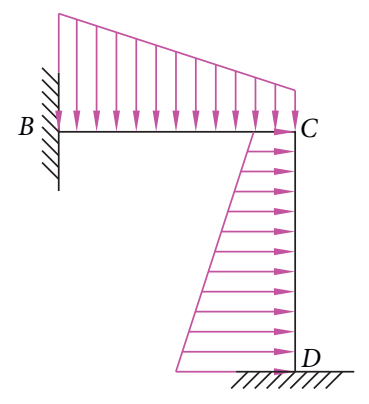

(a)

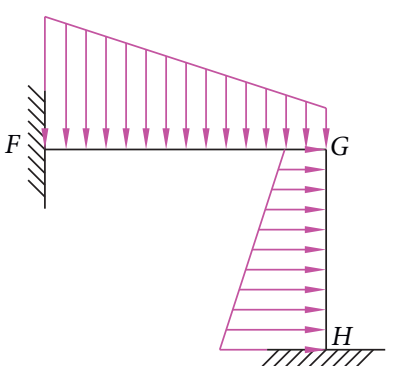

(b)

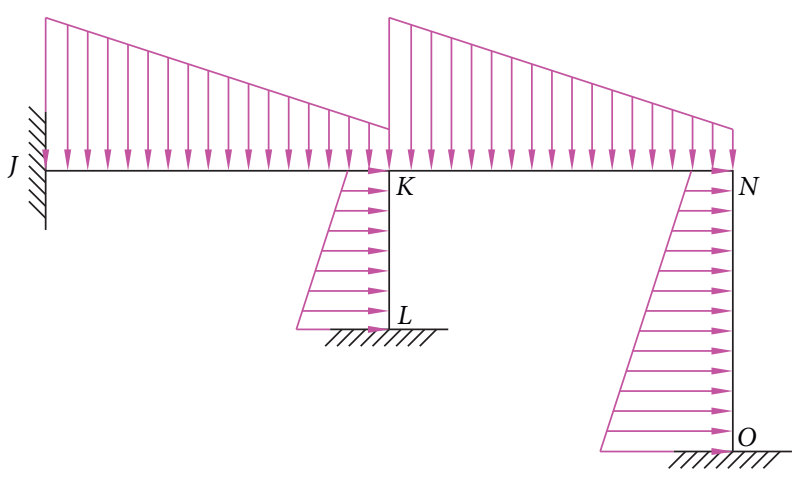

(c)

FIGURE 4: Simplified figure of the load effects of the ASCL above the slip surfaces: (a) simplified figure of the load effects of BCD; (b) simplified figure of the load effects of FGH; (c) simplified figure of the load effects of JKLNO.

complex geological conditions and the layout of the structures. The bottom boundary conditions of the antislide members $(A B, L M$, and $O P)$ below the slip surfaces are considered to be the hinge support due to the complete layer of the slip bed and the shallow anchoring depth in Figure 3. Because the bottoms of the rigid members form the hinge support, the members rotate around their bottoms. Because the bottoms of the elastic members form the hinge support, the effects of the structures should be calculated and analysed by considering the hinge support, which is the boundary condition at the bottom of the structures.

Ignoring the axial deformation of the antimembers, their combinations in the ASCL above the slip surfaces are presented by $D E F$ and $H I J$ in Figure 3. If $D E F$ is the rigid combination, $D E$ is a vertical rigid member and $E F$ is a horizontal rigid member. Furthermore, while DEF (rigid combination) bears the axial force, shear force, and bending moment on the slip surfaces, $D E$ will rotate around some node, and $E F$ will rotate similarly around some node. Thus, $D E F$ (rigid combination) can only rotate around Node $E$, which is the only common joint between $D E$ and $E F$. The structural stress of $D E F$ (rigid combination) is shown in Figure 5.

Otherwise, if $D E F$ is the elastic combination, $D E$ is the vertical elastic member and $E F$ is the horizontal elastic member. Node $E$ cannot move along the horizontal and vertical directions due to the $D E$ and $E F$, which constrains the horizontal and vertical displacement of Node $E$. Therefore, DEF (elastic combination) rotates around Node $E$, but no horizontal and vertical displacement occurs, and the rigid Node $E$ maintains its right angle. The structural stress of $D E F$ (elastic combination) is shown in Figure 6.

The internal stress at Node $E$ of $D E F$ is shown in Figure 7, the boundary condition at Node $E$ of $D E F$ is shown in formula (1), and the equilibrium condition of the internal stress at Node $E$ of $D E F$ is shown in formula (2).

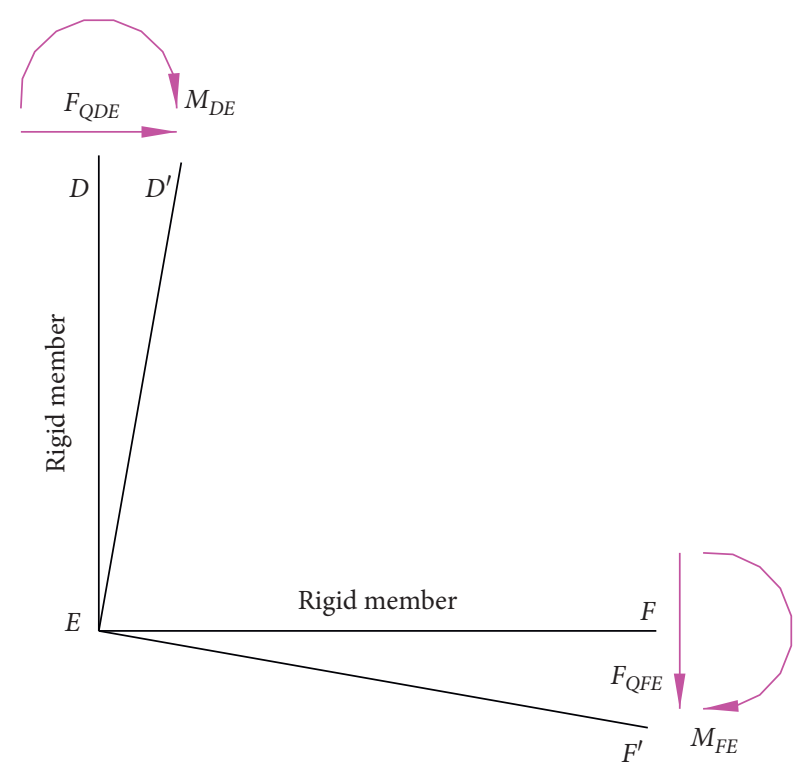

FIgURE 5: The structural stress of $D E F$ (rigid combination). Due to the shear force and bending moment of the ends in the rigid members, the angular displacement of the ends will occur, but no lateral deflection deformation will occur.

$$
\begin{gathered}
x_{E}=y_{E}=0, \\
\angle D E D^{\prime}=\angle F E F^{\prime}, \\
\angle D E F=\angle D^{\prime} E F^{\prime}=\frac{\pi}{2},
\end{gathered}
$$

where $x_{E}$ is the horizontal displacement of Node $E, y_{E}$ is the vertical displacement of Node $E, \angle D E D^{\prime}$ is the intersection angle between $D E$ and $D^{\prime} E, \angle F E F^{\prime}$ is the intersection angle between $F E$ and $F^{\prime} E, \angle D E F$ is the intersection angle between $D E$ and $F E$, and $\angle D^{\prime} E F^{\prime}$ is the intersection angle between $D^{\prime} E$ and $F^{\prime} E$. 


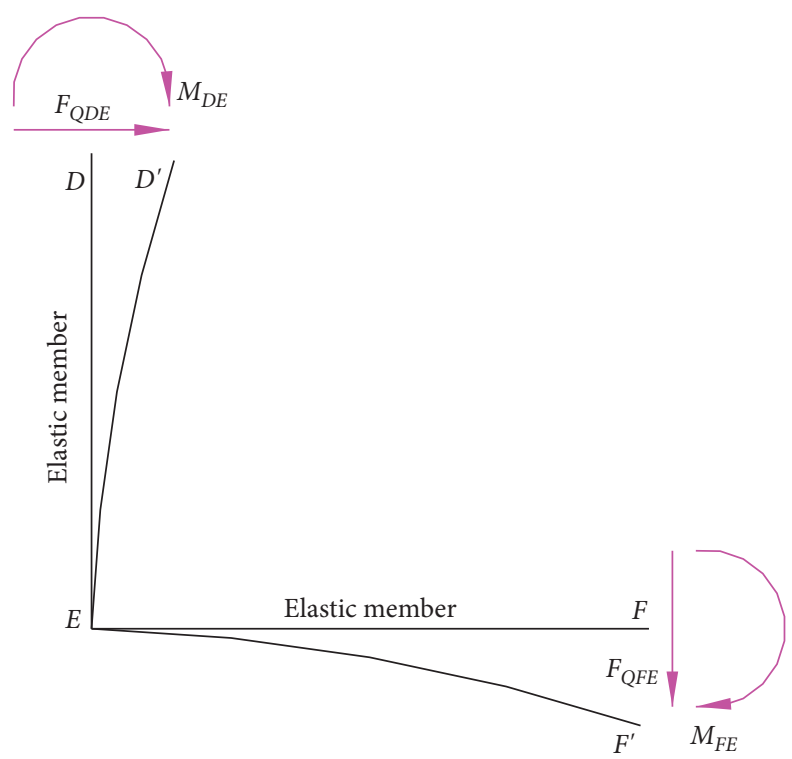

Figure 6: Structural stress of DEF (elastic combination). Due to the shear force and bending moment of the ends in the elastic members, angular displacement and lateral deflection deformations of the ends will occur.

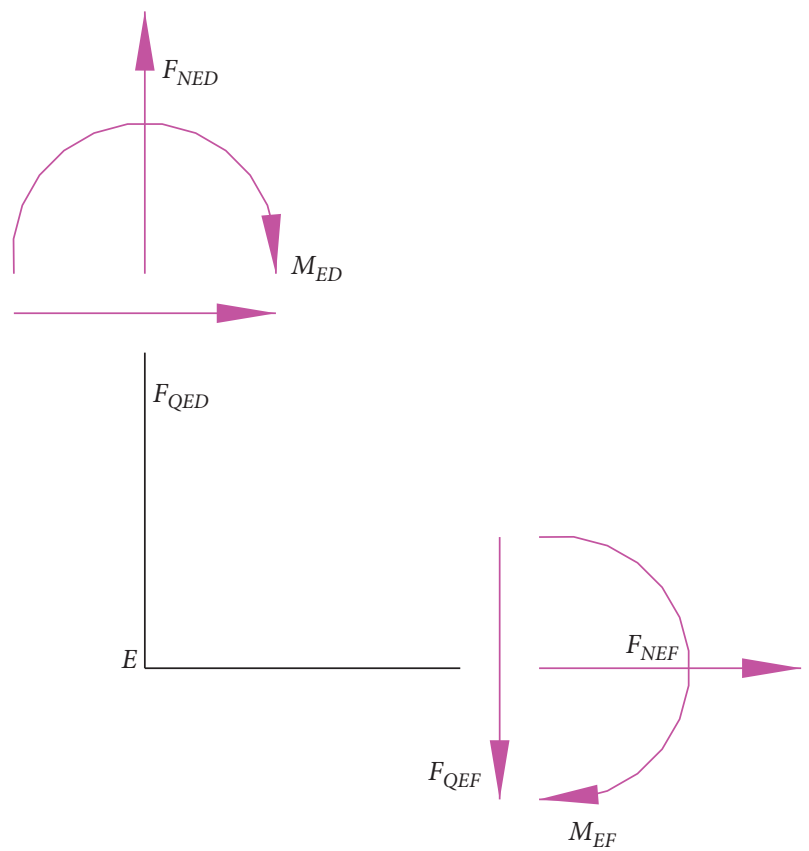

Figure 7: The internal stress at Node $E$ of $D E F$. The resultant force at Node $E$ of $D E F$ along the $x$-direction and $y$-direction is 0 , while the resultant moment at Node $E$ of $D E F$ is 0 .

$$
\begin{aligned}
\sum F_{x} & =0, \\
F_{Q E D}+F_{N E F} & =0, \\
\sum F_{y} & =0, \\
F_{N E D}-F_{Q E F} & =0, \\
\sum M_{E} & =0, \\
M_{E D}+M_{E F} & =0,
\end{aligned}
$$

where $\sum F_{x}$ is the resultant force at Node $E$ along the $x$ direction, $\sum F_{y}$ is the resultant force at Node $E$ along the $y$ direction, $\sum M_{E}$ is the resultant moment at Node $E, F_{Q E D}$ is the shear force at Node $E$ along the $E D$ direction, $F_{Q E F}$ is the shear force at Node $E$ along the $E F$ direction, $F_{N E D}$ is the axial force of $D E, F_{N E F}$ is the axial force of $E F, M_{E D}$ is the resultant moment at Node $E$ along the $E D$ direction, and $M_{E F}$ is the resultant moment at Node $E$ along the $E F$ direction.

\section{Analytical Calculations}

\subsection{Analytical Calculation of the Structural Stress above the Slip Surfaces}

3.1.1. Analytical Calculation of the Structural Stress of BCD. The load decomposition of $B C D$ is shown in Figure 8, and the analytical calculation of the structural stress of $B C D$ is shown in formulas (3) and (4). The analytical calculation of the structural stress of $F G H$ is the same as that of $B C D$ and is not repeated here.

where $M_{B C}$ is the bending moment at Node $B$ along the $B C$ direction, $M_{C B}$ is the bending moment at Node $C$ along the $C B$ direction, $M_{D C}$ is the bending moment at Node $D$ along the $D C$ direction, $M_{C D}$ is the bending moment at Node $C$ along the $C D$ direction, $F_{Q B C}$ is the shear force at Node $B$ along the $B C$ direction, $F_{Q C B}$ is the shear force at Node $C$ along the $C B$ direction, $F_{Q D C}$ is the shear force at Node $D$ along the $D C$ direction, $F_{Q C D}$ is the shear force at Node $C$ along the $C D$ direction, $F_{N C B}$ is the axial force of $B C, F_{N C D}$ is the axial force of $C D, \theta_{C 1}$ is the angular displacement of $C_{1}$, $\theta_{C 2}$ is the angular displacement of $C_{2}, q_{B C}$ is the rectangular load of the load decomposition of $B C, q_{B C}^{\prime}$ is the maximum of the triangular load of the load decomposition of $B C, q_{C D}$ is the rectangular load of the load decomposition of $C D, q_{C D}^{\prime}$ is the maximum of the triangular load of the load decomposition of $C D, i_{B C}$ is the linear stiffness of $B C, i_{C D}$ is the 


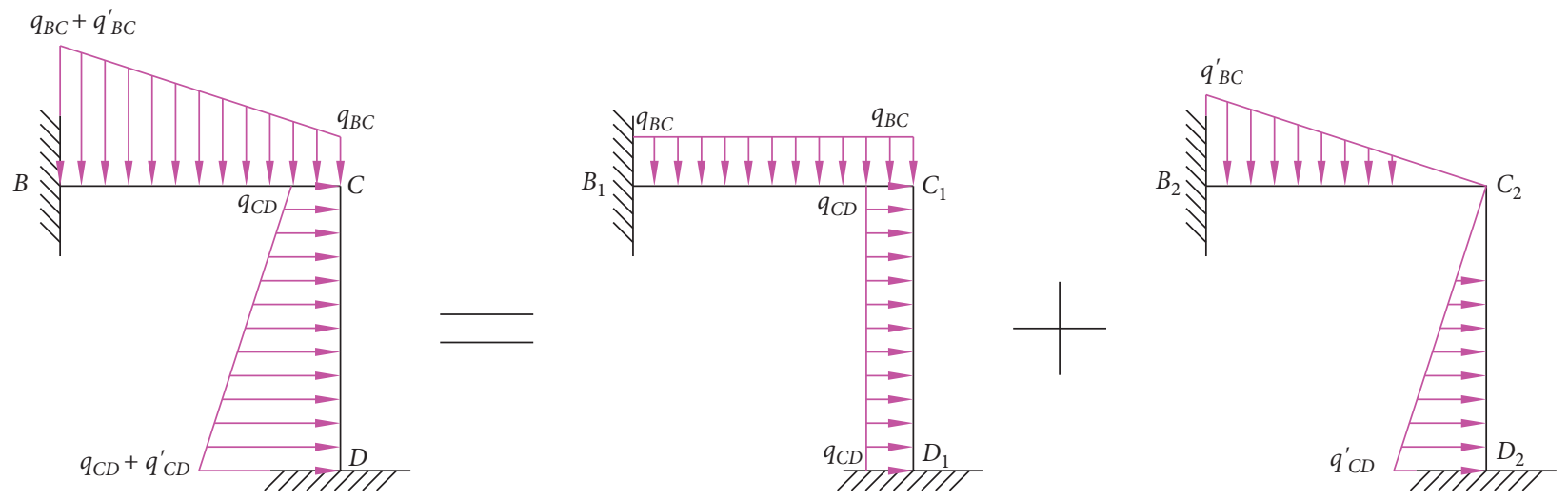

Figure 8: The load decomposition of $B C D$ : (a) trapezoidal load; (b) rectangular load; (c) triangular load.

linear stiffness of $C D, l_{B C}$ is the length of $B C$, and $l_{C D}$ is the length of $C D$.

$$
\begin{aligned}
& {\left[\begin{array}{l}
M_{B C} \\
M_{C B} \\
M_{D C} \\
M_{C D} \\
F_{Q B C} \\
F_{Q C B} \\
F_{Q D C}
\end{array}\right]=\left[\begin{array}{cccc}
2 i_{B C} & 2 i_{B C} & -\frac{q_{B C} l_{B C}^{2}}{12} & -\frac{q_{B C}^{\prime} l_{B C}^{2}}{20} \\
4 i_{B C} & 4 i_{B C} & -\frac{q_{B C} l_{B C}^{2}}{12} & -\frac{q_{B C}^{\prime} l_{B C}^{2}}{30} \\
2 i_{C D} & 2 i_{C D} & -\frac{q_{C D} l_{C D}^{2}}{12} & -\frac{q_{C D}^{\prime} l_{C D}^{2}}{20} \\
4 i_{C D} & 4 i_{C D} & -\frac{q_{C D} l_{C D}^{2}}{12} & -\frac{q_{C D}^{\prime} l_{C D}^{2}}{30} \\
-\frac{6 i_{B C}}{l_{B C}} & -\frac{6 i_{B C}}{l_{B C}} & \frac{q_{B C} l_{B C}}{2} & -\frac{7 q_{B C}^{\prime} l_{B C}}{20} \\
-\frac{6 i_{B C}}{l_{B C}} & -\frac{6 i_{B C}}{l_{B C}} & -\frac{q_{B C} l_{B C}}{2} & -\frac{3 q_{B C}^{\prime} l_{B C}}{20} \\
6 i_{C D} & -\frac{6 i_{C D}}{l_{C D}} & \frac{q_{C D} l_{C D}}{2} & -\frac{7 q_{C D}^{\prime} l_{C D}}{20} \\
-\frac{6 i_{C D}}{l_{C D}} & -\frac{6 i_{C D}}{l_{C D}} & -\frac{q_{C D} l_{C D}}{2} & -\frac{3 q_{C D}^{\prime} l_{C D}}{20}
\end{array}\right]\left[\begin{array}{c}
\theta_{C 1} \\
\theta_{C 1} \\
1 \\
1
\end{array}\right],} \\
& \theta_{C_{1}}=-\frac{q_{B C} l_{B C}^{2}+q_{C D} l_{C D}^{2}}{48\left(i_{B C}+i_{C D}\right)}, \\
& \theta_{C_{2}}=-\frac{q_{B C}^{\prime} l_{B C}^{2}+q_{C D}^{\prime} l_{C D}^{2}}{120\left(i_{B C}+i_{C D}\right)}, \\
& F_{N C B}=-F_{Q C D} \text {, } \\
& F_{N C D}=F_{Q C B} \text {, }
\end{aligned}
$$

3.1.2. Analytical Calculation of the Structural Stress of JKLNO. The load decomposition of JKLNO is shown in
Figure 9, and the analytical calculation of the structural stress of JKLNO is shown in formulas (5) (8). 


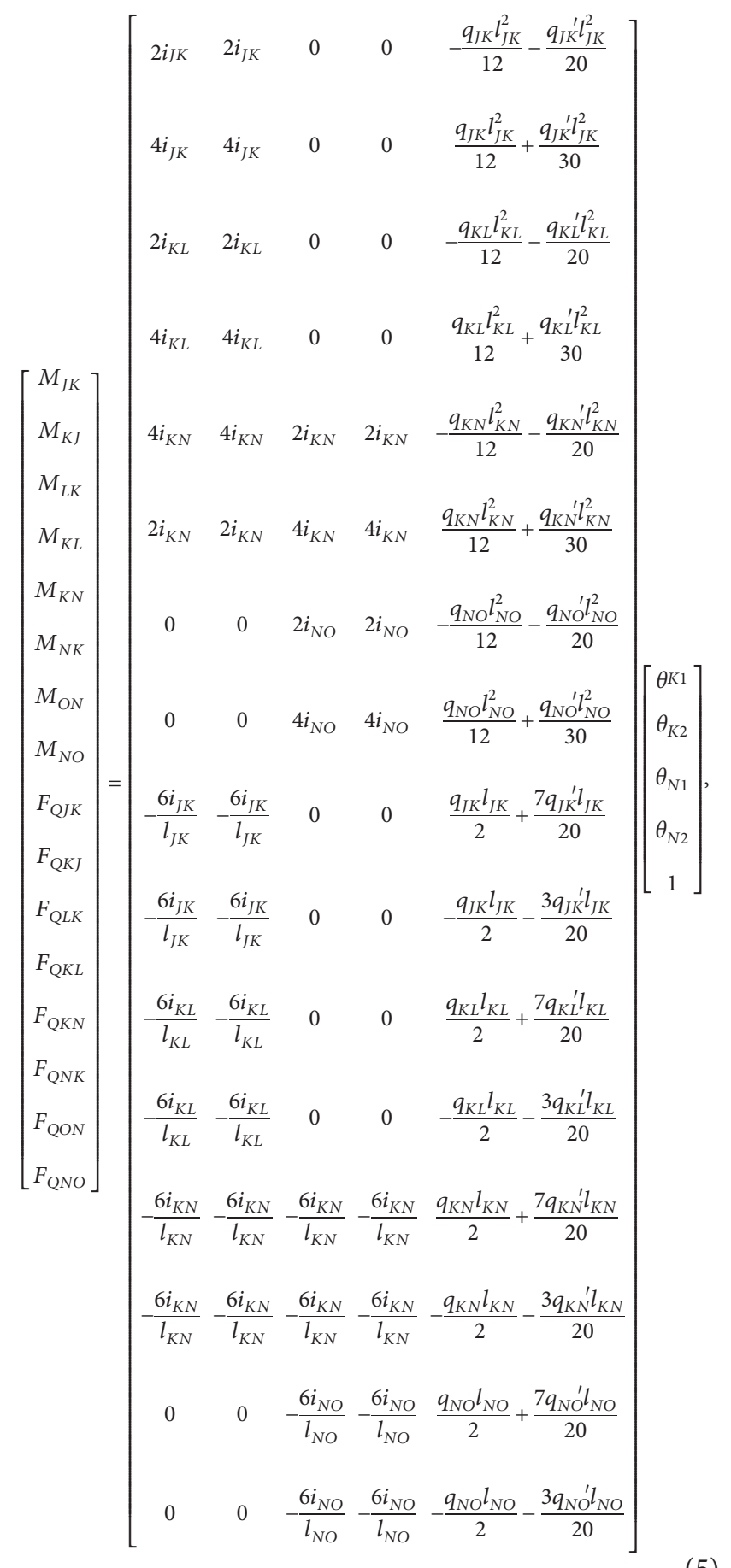

$$
\begin{gathered}
{\left[\begin{array}{cc}
4 i_{J K}+4 i_{K L}+4 i_{K N} & 2 i_{K N} \\
2 i_{K N} & 4 i_{K N}+4 i_{N O}
\end{array}\right]\left[\begin{array}{l}
\theta_{K_{1}} \\
\theta_{N_{1}}
\end{array}\right]} \\
=\left[\begin{array}{c}
\frac{q_{K N} l_{K N}^{2}-q_{K L} l_{K L}^{2}-q_{J K} l_{J K}^{2}}{12} \\
-\frac{q_{K N} l_{K N}^{2}+q_{N O} l_{N O}^{2}}{12}
\end{array}\right],
\end{gathered}
$$

$$
\begin{aligned}
& {\left[\begin{array}{cc}
4 i_{J K}+4 i_{K L}+4 i_{K N} & 2 i_{K N} \\
2 i_{K N} & 4 i_{K N}+4 i_{N O}
\end{array}\right]\left[\begin{array}{l}
\theta_{K_{2}} \\
\theta_{N_{2}}
\end{array}\right]} \\
& =\left[\begin{array}{c}
\frac{3 q_{K N}^{\prime} l_{K N}^{2}-2 q_{K L}^{\prime} l_{K L}^{2}-2 q_{J K}^{\prime} l_{J K}^{2}}{60} \\
-\frac{q_{K N}^{\prime} l_{K N}^{2}+q_{N O}^{\prime} l_{N O}^{2}}{30}
\end{array}\right], \\
& F_{N K J}=-F_{\mathrm{QNO}}-F_{\mathrm{QKL}} \text {, } \\
& F_{N K L}=F_{Q K J}-F_{Q K N} \text {, } \\
& F_{N K N}=F_{N N K}=-F_{Q N O} \text {, } \\
& F_{N N O}=F_{Q N K} \text {, }
\end{aligned}
$$

3.2. Analytical Calculation of the Structural Stress below the Slip Surfaces. To integrate the structural stress, the horizontal and vertical antislide members are both assumed to be elastic members. The analytical calculation of the structural stress below the slip surfaces is carried out as follows.

3.2.1. Analytical Calculation of the Structural Stress of $A B$ (Elastic Member). The initial effects and stress diagram of $A B$ (elastic member) are shown in Figure 10. Node $B$ on the slip surfaces is taken as the starting point, and the analytical calculation of the displacement and internal stress of the section, which is $x \mathrm{~m}$ distance from Node $B$ along the $B A$ direction, is shown in formulas (9) and (10). The analytical calculation of the structural stress of $L M$ and $O P$ is the same as that of $A B$ and is not repeated here.

where $M_{J K}$ is the bending moment at Node $J$ along the $J K$ direction, $M_{K J}$ is the bending moment at Node $K$ along the $K J$ direction, $M_{L K}$ is the bending moment at Node $L$ along the $L K$ direction, $M_{K L}$ is the bending moment at Node $K$ along the $K L$ direction, $M_{K N}$ is the bending moment at Node $K$ along the $K N$ direction, $M_{N K}$ is the bending moment at Node $N$ along the $N K$ direction, $M_{O N}$ is the bending moment at Node $O$ along the $O N$ direction, $M_{N O}$ is the bending moment at Node $N$ along the $N O$ direction, $F_{Q J K}$ is the shear force at Node $J$ along the JK direction, $F_{Q K J}$ is the shear force at Node $K$ along the $K J$ direction, $F_{Q L K}$ is the shear force at Node $L$ along the $L K$ direction, $F_{Q K L}$ is the shear force at Node $K$ along the $K L$ direction, $F_{Q K N}$ is the shear force at Node $K$ along the $K N$ direction, $F_{Q N K}$ is the shear force at Node $N$ along the $N K$ direction, $F_{Q O N}$ is the shear force at Node $O$ along $O N$ direction, $F_{Q N O}$ is the shear force at Node $N$ along the $N O$ direction, $F_{N K J}$ is the axial force of $J K, F_{N K L}$ is the axial force of $K L, F_{N K N}$ is the axial force of $K N, F_{N N O}$ is the axial force of $N O, \theta_{K 1}$ is the angular displacement of $K_{1}$, $\theta_{K 2}$ is the angular displacement of $K_{2}, \theta_{N 1}$ is the angular displacement of $N_{1}, \theta_{N 2}$ is the angular displacement of $N_{2}$, $q_{J K}$ is the rectangular load of the load decomposition of $J K$, $q_{J K}^{\prime}$ is the maximum of the triangular load of the load decomposition of $J K, q_{K N}$ is the rectangular load of the load 


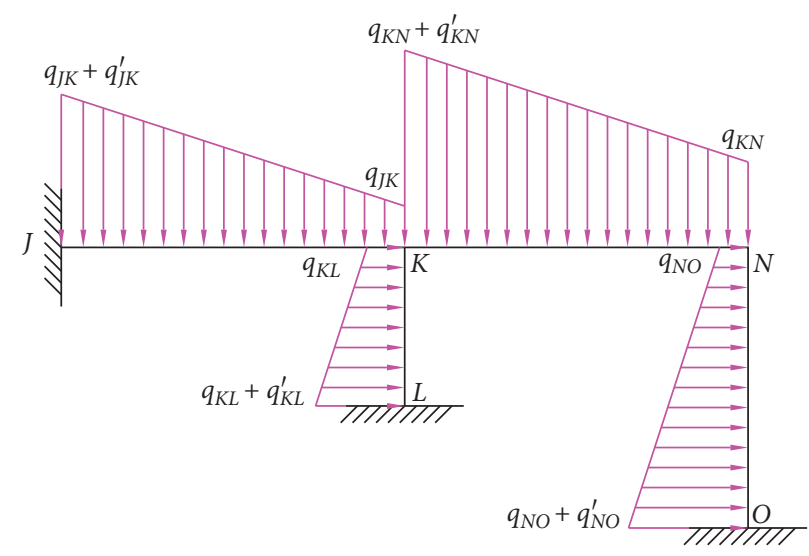

(a)

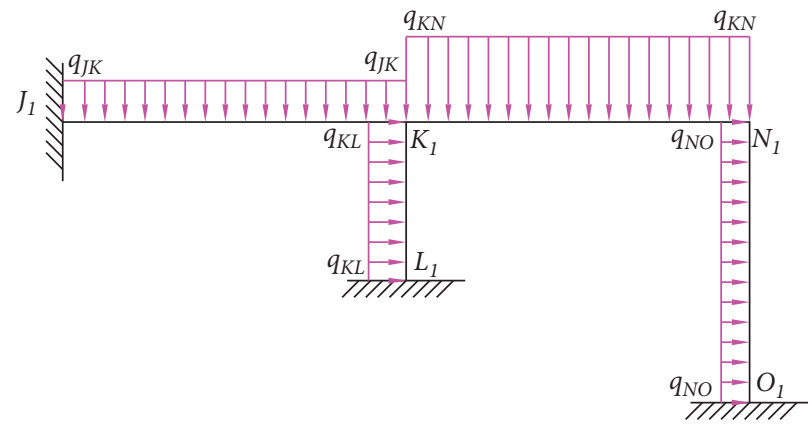

(b)

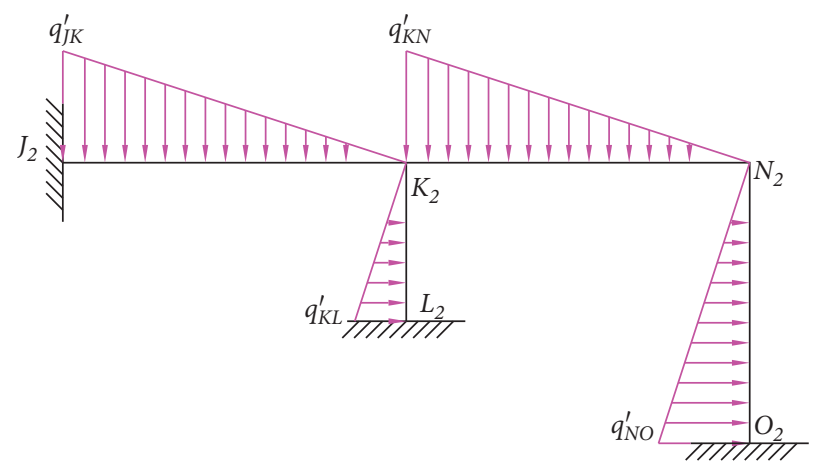

(c)

FIgURE 9: The load decomposition of JKLNO: (a) trapezoidal load; (b) rectangular load; (c) triangular load.

decomposition of $K N, q_{K N}^{\prime}$ is the maximum of the triangular load of the load decomposition of $K N, q_{K L}$ is the rectangular load of the load decomposition of $K L, q_{K L}^{\prime}$ is the maximum of the triangular load of the load decomposition of $K L, q_{N O}$ is the rectangular load of the load decomposition of $\mathrm{NO}, q_{\mathrm{NO}}$ is the maximum of the triangular load of the load decomposition of $N O, i_{J K}$ is the linear stiffness of $J K, i_{K L}$ is the linear stiffness of $K L, i_{K N}$ is the linear stiffness of $K N, i_{N O}$ is the linear stiffness of $N O, l_{J K}$ is the length of $J K, l_{K L}$ is the length of $K L, l_{K N}$ is the length of $K N$, and $l_{N O}$ is the length of $N O$.

$$
\begin{aligned}
& y(x)=\varphi_{1 A B} y_{B A}+\varphi_{2 A B} \frac{\varphi_{B A}}{\beta_{A B}}+\varphi_{3 A B} \frac{M_{B A}}{E_{A B} I_{A B} \beta_{A B}^{2}}+\varphi_{4 A B} \frac{F_{\mathrm{QBA}}}{E_{A B} I_{A B} \beta_{A B}^{2}}, \\
& \varphi(x)=\left(-4 \beta_{A B} \varphi_{4 A B}\right) y_{A B}+\varphi_{1 A B} \varphi_{B A}+\varphi_{2 A B} \frac{M_{B A}}{E_{A B} I_{A B} \beta_{A B}}+\varphi_{3 A B} \frac{F_{Q B A}}{E_{A B} I_{A B} \beta_{A B}^{2}}, \\
& M(x)=E_{A B} I_{A B}\left[\left(-4 \beta_{A B}^{2} \varphi_{3 A B}\right) y_{B A}+\left(-4 \beta_{A B} \varphi_{4 A B}\right) \varphi_{B A}+\varphi_{1 A B} \frac{M_{B A}}{E_{A B} I_{A B}}+\varphi_{2 A B} \frac{F_{Q B A}}{E_{A B} I_{A B} \beta_{A B}}\right], \\
& Q(x)=E_{A B} I_{A B}\left[\left(-4 \beta_{A B}^{2} \varphi_{2 A B}\right) y_{B A}+\left(-4 \beta_{A B}^{2} \varphi_{3 A B}\right) \varphi_{B A}+\left(-4 \beta_{A B} \varphi_{4 A B}\right) \frac{M_{B A}}{E_{A B} I_{A B}}+\varphi_{1 A B} \frac{F_{Q B A}}{E_{A B} I_{A B} \beta_{A B}}\right],
\end{aligned}
$$

where $y(x)$ is the vertical displacement of the section that is $x \mathrm{~m}$ distance from Node $B$ along the $B A$ direction, $\varphi(x)$ is the angular displacement of the section that is $x \mathrm{~m}$ distance from Node $B$ along the $B A$ direction, $M(x)$ is the bending moment of the section that is $x \mathrm{~m}$ distance from Node $B$ along the $B A$ direction, $Q(x)$ is the shear force of the section that is $x \mathrm{~m}$ distance from Node $B$ along the $B A$ direction, $y_{B A}$ is the initial vertical displacement of Node $B, \varphi_{B A}$ is the initial angular displacement of Node $B, M_{B A}$ is the initial bending moment of Node $B, F_{Q B A}$ is the initial shear force of 
Node $B, E_{A B}$ is the elastic coefficient of $A B, I_{A B}$ is the section inertial moment of $A B$, and $\beta_{A B}$ is the deformation coefficient of $A B$.

As mentioned before, the boundary condition of Node $A$ is shown in formula (11) considering the bottom of $A B$ (elastic member), which is a hinge support. By calculating formula (11), formula (12) is obtained. Furthermore, formula (12) is plugged into formula (9) to obtain the structural effects of $A B$ (elastic member).

$$
\left\{\begin{array}{l}
\varphi_{1 A B}=\cos \beta_{A B} x \operatorname{ch} \beta_{A B} x, \\
\varphi_{2 A B}=\frac{\sin \beta_{A B} x \operatorname{ch} \beta_{A B} x+\cos \beta_{A B} x \operatorname{sh} \beta_{A B} x}{2} \\
\varphi_{3 A B}=\frac{\sin \beta_{A B} x \operatorname{sh} \beta_{A B} x}{2} \\
\varphi_{4 A B}=\frac{\sin \beta_{A B} x \operatorname{ch} \beta_{A B} x-\cos \beta_{A B} x \operatorname{sh} \beta_{A B} x}{4} \\
\operatorname{sh} \beta_{A B} x=\frac{e^{\beta_{A B} x}-e^{-\beta_{A B} x}}{2} \\
\operatorname{ch}_{A B} x=\frac{e^{\beta_{A B} x}+e^{-\beta_{A B} x}}{2} \\
\beta_{A B}=\left[\frac{K_{V} B_{P(A B)}}{4 E_{A B} I_{A B}}\right]^{(1 / 4)}
\end{array}\right.
$$

where $K_{V}$ is the vertical foundation coefficient of the slip bed, $B_{P(A B)}$ is the calculation width of $A B$, and $e$ is the natural exponent that is equal to $2.718281 \ldots$

$$
\begin{aligned}
& \left\{\begin{array}{l}
M_{A B}=\left.E_{A B} I_{A B}\left[\left(-4 \beta_{A B}^{2} \varphi_{3 A B}\right) y_{B A}+\left(-4 \beta_{A B} \varphi_{4 A B}\right) \varphi_{B A}+\varphi_{1 A B} \frac{M_{B A}}{E_{A B} I_{A B}}+\varphi_{2 A B} \frac{F_{Q B A}}{E_{A B} I_{A B} \beta_{A B}}\right]\right|_{x=l_{A B}}=0, \\
y_{A}=\left.\left[\varphi_{1 A B} y_{B A}+\varphi_{2 A B} \frac{\varphi_{B A}}{\beta_{A B}}+\varphi_{3 A B} \frac{M_{B A}}{E_{A B} I_{A B} \beta_{A B}^{2}}+\varphi_{4 A B} \frac{F_{Q B A}}{E_{A B} I_{A B} \beta_{A B}^{3}}\right]\right|_{x=l_{A B}}=0,
\end{array}\right. \\
& \left\{\begin{array}{l}
y_{B A}=\left.\left(\frac{M_{B A}}{E_{A B} I_{A B} \beta_{A B}^{2}} \frac{4 \varphi_{3 A B} \varphi_{4 A B}+\varphi_{1 A B} \varphi_{2 A B}}{4 \varphi_{2 A B} \varphi_{3 A B}-4 \varphi_{1 A B} \varphi_{4 A B}}+\frac{F_{Q B A}}{E_{A B} I_{A B} \beta_{A B}^{3}} \frac{4 \varphi_{4 A B}^{2}+\varphi_{2 A B}^{2}}{4 \varphi_{2 A B} \varphi_{3 A B}-4 \varphi_{1 A B} \varphi_{4 A B}}\right)\right|_{x=l_{A B}}, \\
\varphi_{B A}=\left.\left(-\frac{M_{B A}}{E_{A B} I_{A B} \beta_{A B}} \frac{\varphi_{1 A B}^{2}+4 \varphi_{3 A B}^{2}}{4 \varphi_{2 A B} \varphi_{3 A B}-4 \varphi_{1 A B} \varphi_{4 A B}}-\frac{F_{Q B A}}{E_{A B} I_{A B} \beta_{A B}^{2}} \frac{4 \varphi_{3 A B} \varphi_{4 A B}+\varphi_{1 A B} \varphi_{2 A B}}{4 \varphi_{2 A B} \varphi_{3 A B}-4 \varphi_{1 A B} \varphi_{4 A B}}\right)\right|_{x=l_{A B}},
\end{array}\right.
\end{aligned}
$$

where $l_{A B}$ is the length of $A B, M_{A B}$ is the bending moment at Node $A$ along the $A B$ direction, and $y_{A}$ is the vertical displacement of Node $A$.

3.2.2. Analytical Calculation of the Structural Stress of DEF (Elastic Combination). The boundary conditions at Node $E$ of DEF (elastic combination) are shown in formulas
(13) (15), and the equilibrium condition of the internal stress at Node $E$ of $D E F$ (elastic combination) is shown in formula (16). According to the boundary conditions, the initial effects of $D E$ and $E F$ are solved. The effects of the members are obtained considering their initial effects, which are plugged into the displacement and internal stress calculations of the members. The analytical calculation of the structural stress of the HIJ is the same as that of the DEF and 
is not repeated here:

$$
\left\{\begin{array}{l}
x_{E D}=\left.\left(\varphi_{1 D E} x_{D E}+\varphi_{2 D E} \frac{\varphi_{D E}}{\beta_{D E}}+\varphi_{3 D E} \frac{M_{D E}}{E_{D E} I_{D E} \beta_{D E}^{2}}+\varphi_{4 D E} \frac{F_{Q D E}}{E_{D E} I_{D E} \beta_{D E}^{3}}\right)\right|_{y=l_{D E}}=0, \\
y_{E F}=\left.\left(\varphi_{1 E F} y_{F E}+\varphi_{2 E F} \frac{\varphi_{F E}}{\beta_{E F}}+\varphi_{3 E F} \frac{M_{F E}}{E_{E F} I_{E F} \beta_{E F}^{2}}+\varphi_{4 E F} \frac{F_{Q F E}}{E_{E F} I_{E F} \beta_{E F}^{3}}\right)\right|_{x=l_{E F}}=0,
\end{array}\right.
$$

where $x_{E D}$ is the horizontal displacement at Node $E$ along the $E D$ direction, $x_{D E}$ is the initial horizontal displacement at Node $D, \varphi_{D E}$ is the initial angular displacement at Node $D$, $M_{D E}$ is the initial bending moment at Node $D, F_{Q D E}$ is the initial shear force at Node $D, E_{D E}$ is the elastic coefficient of $D E, I_{D E}$ is the section inertial moment of $D E, \beta_{D E}$ is the deformation coefficient of $D E, l_{D E}$ is the length of $D E, y_{E F}$ is the vertical displacement at Node $E$ along the $E F$ direction, $\varphi_{F E}$ is the initial angular displacement at Node $F, M_{F E}$ is the initial bending moment at Node $F, F_{Q F E}$ is the initial shear force at Node $F, E_{E F}$ is the elastic coefficient of $E F, I_{E F}$ is the section inertial moment of $E F, \beta_{E F}$ is the deformation coefficient of $E F$, and $l_{E F}$ is the length of $E F$.

$$
\begin{aligned}
\varphi_{E D} & =\varphi_{E F}, \\
\varphi_{E D} & =\left.\left[\left(-4 \beta_{D E} \varphi_{4 D E}\right) x_{D E}+\varphi_{1 D E} \varphi_{D E}+\varphi_{2 D E} \frac{M_{D E}}{E_{D E} I_{D E} \beta_{D E}}+\varphi_{3 D E} \frac{F_{Q D E}}{E_{D E} I_{D E} \beta_{D E}^{2}}\right]\right|_{y=l_{D E}} \\
\varphi_{E F} & =\left.\left[\left(-4 \beta_{E F} \varphi_{4 E F}\right) y_{F E}+\varphi_{1 E F} \varphi_{F E}+\varphi_{2 E F} \frac{M_{F E}}{E_{E F} I_{E F} \beta_{E F}}+\varphi_{3 E F} \frac{F_{Q F E}}{E_{E F} I_{E F} \beta_{E F}^{2}}\right]\right|_{x=l_{E F}}
\end{aligned}
$$

where $\varphi_{E D}$ is the angular displacement at Node $E$ along the $E D$ direction and $\varphi_{E F}$ is the angular displacement at Node $E$ along the EF direction.

$$
\begin{aligned}
& \sum M_{E}=0, \\
& M_{E D}+M_{E F}=0, \\
& M_{E D}=\left.\left\{E_{D E} I_{D E}\left[\left(-4 \beta_{D E}^{2} \varphi_{3 D E}\right) x_{D E}+\left(-4 \beta_{D E} \varphi_{4 D E}\right) \varphi_{D E}+\varphi_{1 D E} \frac{M_{D E}}{E_{D E} I_{D E}}+\varphi_{2 D E} \frac{F_{Q D E}}{E_{D E} I_{D E} \beta_{D E}}\right]\right\}\right|_{y=l_{D E}} \\
& M_{E F}=\left.\left\{E_{E F} I_{E F}\left[\left(-4 \beta_{E F}^{2} \varphi_{3 E F}\right) y_{F E}+\left(-4 \beta_{E F} \varphi_{4 E F}\right) \varphi_{F E}+\varphi_{1 E F} \frac{M_{F E}}{E_{E F} I_{E F}}+\varphi_{2 E F} \frac{F_{Q F E}}{E_{E F} I_{E F} \beta_{E F}}\right]\right\}\right|_{x=l_{E F}},
\end{aligned}
$$


where $\sum M_{E}$ is the resultant moment at Node $E, M_{E D}$ is the bending moment at Node $E$ along the ED direction, and
$M_{E F}$ is the bending moment at Node $E$ along the $E F$ direction.

$$
\left\{\begin{array}{l}
\sum F_{x}=0 \\
F_{Q E D}+F_{N E F}=0, \\
\sum F_{y}=0 \\
F_{N E D}-F_{Q E F}=0, \\
F_{Q E D}=\left.\left\{E_{D E} I_{D E}\left[\left(-4 \beta_{D E}^{3} \varphi_{2 D E}\right) x_{D E}+\left(-4 \beta_{D E}^{2} \varphi_{3 D E}\right) \varphi_{D E}+\left(-4 \beta_{D E} \varphi_{4 D E}\right) \frac{M_{D E}}{E_{D E} I_{D E}}+\varphi_{1 D E} \frac{F_{Q D E}}{E_{D E} I_{D E}}\right]\right\}\right|_{y=l_{D E}}, \\
F_{Q E F}=\left.\left\{E_{E F} I_{E F}\left[\left(-4 \beta_{E F}^{3} \varphi_{2 E F}\right) y_{F E}+\left(-4 \beta_{E F}^{2} \varphi_{3 E F}\right) \varphi_{F E}+\left(-4 \beta_{E F} \varphi_{4 E F}\right) \frac{M_{F E}}{E_{E F} I_{E F}}+\varphi_{1 E F} \frac{F_{Q F E}}{E_{E F} I_{E F}}\right]\right\}\right|_{x=l_{E F}},
\end{array}\right.
$$

where $\sum F x$ is the resultant force at Node $E$ along the $x$ direction, $\sum F y$ is the resultant force at Node $E$ along the $y$ direction, $F_{Q E D}$ is the shear force at Node $E$ along the $E D$ direction, $F_{Q E F}$ is the shear force at Node $E$ along the $E F$ direction, $F_{N E D}$ is the axial force of $D E, F_{N E F}$ is the axial force of $E F, M_{E D}$ is the bending moment at Node $E$ along the $E D$ direction, and $M_{E F}$ is the bending moment at Node $E$ along the $E F$ direction.

\section{Engineering Case}

4.1. Engineering Overview. Taking the ASCL of the Houzishi landslides as an example, the stability and internal stress of the antislide structures are calculated and analysed by taking $1 \mathrm{~m}$ (unit width) of the sliding bodies along the transverse direction of the landslides. The layout of the ASCL in the Houzishi landslides is shown in Figure 11.

Landslides are caused by the increasing sliding force of the sliding bodies and the decreasing mechanical properties of the geotechnical materials. The total load of a landslide is assumed to be the dead weight of the sliding bodies plus the ground surface load, which is equal to $100 \mathrm{kN} / \mathrm{m}$.

The sliding bodies are simplified to be massive marls, the sliding zones are simplified to be plastic clays, and the slip beds are simplified to be massive carbonaceous sandstones. The vertical foundation coefficient of the slip beds $\left(K_{V}\right)$ is established to be $875000 \mathrm{kN} / \mathrm{m}^{3}$, and the horizontal foundation coefficient of the slip beds $\left(K_{H}\right)$ is established to be $612500 \mathrm{kN} / \mathrm{m}^{3}$. The mechanical parameters of the geotechnical landslides are shown in Table 1.

As mentioned before, simplifying the horizontal and vertical antislide members below the slip surfaces to be beams under the foundation and embedded in the slip bed, the analytical calculation of the structural stress is carried out. The mechanical parameters of the antislide members are shown in Table 2. The judgement method of the mechanical properties of the members embedded in the slip bed is shown in the following formula:where $\beta$ is the deformation coefficient of the member, $K$ is the foundation coefficient of the slip bed, $K_{V}$ is the vertical foundation coefficient of the slip bed, $K_{H}$ is the horizontal foundation coefficient of the slip bed, $h_{2}$ is the anchorage depth of the member that is embedded in the slip bed, and $B_{P}$ is the calculation width of the member.

$$
\beta=\left(\frac{K B_{P}}{4 E I}\right)^{(1 / 4)},
$$

rigid members: $\beta h_{2} \leq 1.0$,

elastic members: $\beta h_{2}>1.0$,

\subsection{Landslide Thrust and Resistance in front of the Structures}

4.2.1. Landslide Thrust. The implicit solution of the unbalanced thrust method (transfer coefficient method) is an iterative solution. The landslide body is balanced to solve the stability factor $(F s)$ by steadily reducing the strength of the geotechnical material at the bottom of sliding bodies. The solution is determined as follows: first, the sliding force of the left side of the first stick on the top of a sliding body $\left(F_{0}\right)$ is assumed to be zero; second, the landslide thrust of the other stick is calculated according to formulas (18) and (19) until the landslide thrust of the $n$th stick $\left(F_{n}\right)$ is equal to zero. If $F_{n}$ is not equal to zero, $F_{s}$, which is the actual stability factor, should be adjusted until $F_{n}$ is equal to zero [32].

According to the implicit solution of the unbalanced thrust method (transfer coefficient method), the landslide thrust and the sliding resistance of each stick in the slip bodies can be calculated. The landslide thrust of the antislide members is calculated by the sliding force, which is projected onto the horizontal and vertical antislide members. 


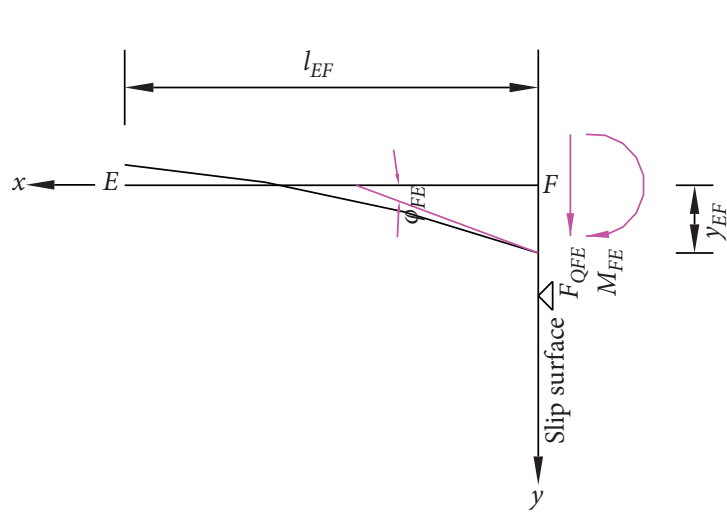

(a)

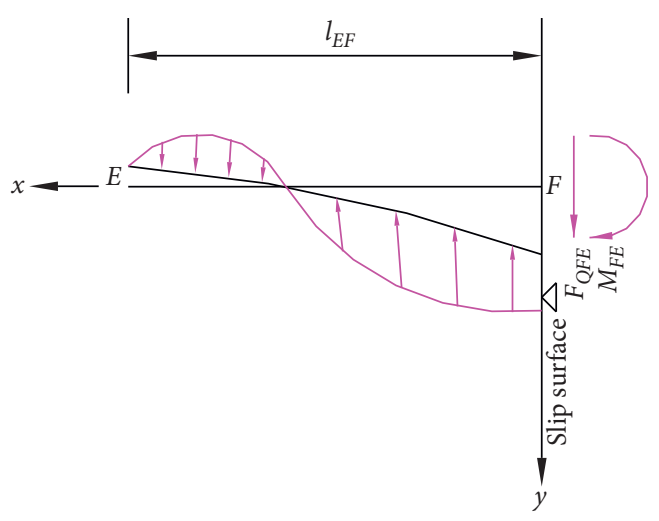

(b)

Figure 10: The initial effects and stress diagram of $A B$ (elastic member): (a) the initial effects of $A B$ (elastic member); (b) the stress diagram of $A B$ (elastic member).

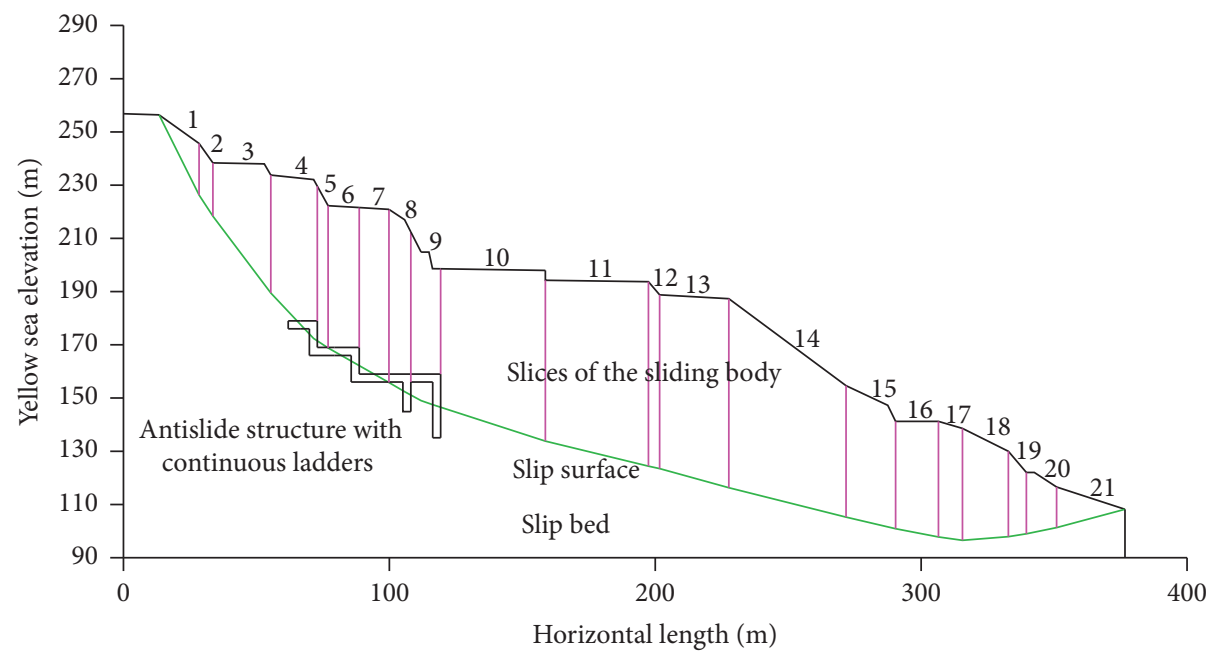

FIgURE 11: The layout of the ASCL in the Houzishi landslide. According to the unbalanced thrust method, the sliding body is divided into 21 sticks to calculate the landslide thrust and resistance along the vertical direction. The horizontal axis represents the horizontal length of the landslide, while the vertical axis represents the Yellow Sea elevation of the landslide.

$$
\left\{\begin{array}{l}
F_{i}=W_{i} \sin \alpha_{i}-\left(W_{i} \cos \alpha_{i} \tan \varphi_{i}+c_{i} l_{i}\right)+\Psi_{i-1} F_{i-1} \\
\Psi_{i-1}=\cos \left(\alpha_{i-1}-\alpha_{i}\right)-\sin \left(\alpha_{i-1}-\alpha_{i}\right) \tan \varphi_{i}
\end{array}\right.
$$

$$
\left\{\begin{array}{l}
F_{i}=T_{i}-\frac{R_{i}}{F_{s}}+\Psi_{i-1}^{\prime} F_{i-1}, \\
T_{i}=W_{i} \sin \alpha_{i}, \\
R_{i}=W_{i} \cos \alpha_{i} \tan \varphi_{i}+c_{i} l_{i}, \\
\Psi_{i-1}^{\prime}=\cos \left(\alpha_{i-1}-\alpha_{i}\right)-\frac{\sin \left(\alpha_{i-1}-\alpha_{i}\right) \tan \varphi_{i}}{F_{s}}
\end{array}\right.
$$

where $F_{i}$ is the landslide thrust of the $i$ th slice, $F_{i-1}$ is the landslide thrust of the $(i-1)$ th slice, $W_{i}$ is the gravity of the $i$ th slice, $\alpha_{i}$ is the horizontal angle of the bottom of the $i$ th slice, $\alpha_{i-1}$ is the horizontal angle of the bottom of the $(i-1)$ th slice, $\varphi_{i}$ is the angle of internal friction of the bottom of the $i$ th slice, $c_{i}$ is the cohesion of the bottom of the $i$ th slice, $l_{i}$ is the length of the bottom of the ith slice, $\psi_{i-1}$ is the transfer coefficient, $\Psi_{i-1}^{\prime}$ is the reduced transfer coefficient, $T_{i}$ is the sliding force of the $i$ th slice, $R_{i}$ is the sliding resistance of the $i$ th slice, and $F_{s}$ is the stability factor.

4.2.2. Resistance in front of the Structures. The passive earth pressure in front of the structures is described in formula (20) [33]. An infinite passive earth pressure is not realistic, even if the ground above the structures is close to horizontal and the friction between the antislide structures and the geotechnical is ignored. Therefore, the resistance of the horizontal antislide members is set to be the horizontal projection of the excess sliding force in the case of ultimate status [34]. 
TABLE 1: The mechanical parameters of the geotechnical landslides.

\begin{tabular}{|c|c|c|c|c|c|c|c|c|}
\hline $\begin{array}{l}\text { Landslide } \\
\text { location }\end{array}$ & Material & $\begin{array}{c}\text { Density } \\
\left(\mathrm{kN} / \mathrm{m}^{3}\right)\end{array}$ & $\begin{array}{c}\text { Elastic } \\
\text { modulus } \\
(\mathrm{MPa})\end{array}$ & $\begin{array}{l}\text { Compressive } \\
\text { strength }(\mathrm{MPa})\end{array}$ & $\begin{array}{c}\text { Tensile } \\
\text { strength } \\
(\mathrm{MPa})\end{array}$ & $\begin{array}{c}\text { Cohesion } \\
(\mathrm{MPa})\end{array}$ & $\begin{array}{l}\text { Angle of } \\
\text { internal } \\
\text { friction }\left(^{\circ}\right)\end{array}$ & Poisson's ratio \\
\hline $\begin{array}{l}\text { Sliding } \\
\text { bodies }\end{array}$ & Marls & 23 & 3800 & 20 & 1.4 & 0.5 & 35 & 0.3 \\
\hline Sliding zone & Plastic clays & 18.5 & 16 & - & - & 0.03 & 20 & 0.35 \\
\hline Slip beds & $\begin{array}{c}\text { Carbonaceous } \\
\text { sandstones }\end{array}$ & 25 & 11000 & 83.75 & 2.475 & 1.1 & 44 & 0.26 \\
\hline
\end{tabular}

TABLE 2: The mechanical parameters of the antislide members.

\begin{tabular}{|c|c|c|c|c|c|c|c|c|}
\hline \multirow[b]{2}{*}{$\begin{array}{l}\text { Sequence } \\
\text { number }\end{array}$} & \multirow[b]{2}{*}{ Member } & \multirow[b]{2}{*}{$\begin{array}{c}\text { Member } \\
\text { length }(\mathrm{m})\end{array}$} & \multicolumn{2}{|c|}{ Partition length } & \multirow{2}{*}{$\begin{array}{c}\text { Section size } \\
(\text { length } \times \text { width, } \mathrm{m}) ; \\
\text { mechanical properties of } \\
\text { the members }\end{array}$} & \multirow{2}{*}{$\begin{array}{l}\text { Strength of } \\
\text { concrete; } \\
\text { Poisson's ratio }\end{array}$} & \multirow[b]{2}{*}{$\begin{array}{l}\text { Strength of } \\
\text { rebar }\end{array}$} & \multirow[b]{2}{*}{$\begin{array}{c}\text { Elastic } \\
\text { modulus }(\mathrm{MPa})\end{array}$} \\
\hline & & & $\begin{array}{l}\text { Partition } \\
\text { member }\end{array}$ & $\begin{array}{l}\text { Length } \\
(\mathrm{m})\end{array}$ & & & & \\
\hline \multirow{2}{*}{1} & \multirow{2}{*}{$A C$} & \multirow{2}{*}{9.434} & $A B$ & 4.717 & $3 \times 3$; (elastic member) & \multirow{15}{*}{ C40; 0.2} & \multirow{15}{*}{$\begin{array}{l}\text { HRB500; } \\
\text { HRB400 }\end{array}$} & \multirow{15}{*}{$2.6 \times 10^{4}$} \\
\hline & & & $B C$ & 4.717 & $3 \times 3 ;(-)$ & & & \\
\hline \multirow{2}{*}{2} & \multirow{2}{*}{$C E$} & \multirow{2}{*}{10.000} & $C D$ & 5.002 & $3 \times 3 ;(-)$ & & & \\
\hline & & & $D E$ & 4.998 & $3 \times 3 ;$ (elastic member) & & & \\
\hline \multirow{2}{*}{3} & \multirow{2}{*}{$E G$} & \multirow{2}{*}{15.752} & $E F$ & 7.876 & $3 \times 3$; (elastic member) & & & \\
\hline & & & $F G$ & 7.876 & $3 \times 3 ;(-)$ & & & \\
\hline \multirow{3}{*}{4} & \multirow{3}{*}{ GI } & \multirow{3}{*}{10.000} & $G H$ & 4.479 & $3 \times 3 ;(-)$ & & & \\
\hline & & & $H I$ & 5.521 & $3 \times 3$; (elastic member $)$ & & & \\
\hline & & & $I J$ & 9.708 & $3 \times 3$; (elastic member) & & & \\
\hline \multirow[t]{2}{*}{5} & \multirow[t]{2}{*}{$I N$} & \multirow[t]{2}{*}{30.624} & $J K$ & 9.708 & $3 \times 3 ;(-)$ & & & \\
\hline & & & $K N$ & 11.208 & $3 \times 3 ;(-)$ & & & \\
\hline \multirow{2}{*}{6} & \multirow{2}{*}{$K M$} & \multirow{2}{*}{12.624} & $K L$ & 5.562 & $3 \times 3 ;(-)$ & & & \\
\hline & & & $L M$ & 7.062 & $3 \times 3$; (elastic member $)$ & & & \\
\hline \multirow{2}{*}{7} & \multirow{2}{*}{$N P$} & \multirow{2}{*}{22.414} & NO & 10.457 & $3 \times 3 ;(-)$ & & & \\
\hline & & & $O P$ & 11.957 & $3 \times 3$; (elastic member $)$ & & & \\
\hline
\end{tabular}

$$
\begin{aligned}
& E_{P}=\frac{1}{2} \gamma_{1} h_{1}^{2} \lambda_{0}, \\
& \lambda_{0}=\frac{\cos ^{2}\left(\varphi_{1}+\alpha\right)}{\cos ^{2} \alpha \cdot \cos (\alpha-\delta)\left[1+\sqrt{\left(\sin \left(\varphi_{1}+\delta\right) \cdot \sin \left(\varphi_{1}+i\right) / \cos (\alpha-\delta) \cdot \cos (\alpha-i)\right)}\right]^{2}},
\end{aligned}
$$

where $E_{P}$ is the passive earth pressure in front of the structure, $\gamma_{1}$ is the unit weight of the geotechnical material in front of the structure, $h_{1}$ is the stress height of the structure in the sliding body, $\lambda_{0}$ is the coefficient of passive earth pressure of the structure, $\varphi_{1}$ is the angle of internal friction in front of the structure, $\delta$ is the friction angle of the structural back, $\alpha$ is the intersection angle between the back and vertical directions of the structure, and $i$ is the ground angle of the structure.

4.2.3. Calculation Results of the Sliding Force and Resistance. By using the implicit solution of the unbalanced thrust method (transfer coefficient method), the distributed line load on the antislide members is determined and shown in Table 3.
4.3. Elastic Resistance below the Slip Surfaces. The analytical solution of the elastic resistance below the slip surfaces is shown in formula (21), and the numerical solution of the interaction between the antislide members and slip bed is shown in formula (22):

$$
\begin{aligned}
& \left\{\begin{array}{l}
\sigma_{x}=-K_{V} B_{P} y(x), \\
\sigma_{y}=-K_{H} B_{P} x(y),
\end{array}\right. \\
& \left\{\begin{array}{l}
q_{x}=\frac{\mathrm{d} Q(y)}{\mathrm{d} y}, \\
q_{y}=\frac{\mathrm{d} Q(x)}{\mathrm{d} x},
\end{array}\right.
\end{aligned}
$$


TABLE 3: The distributed line load on the antislide members.

\begin{tabular}{lcccccc}
\hline Sequence number & Structure & Member & Member length $(\mathrm{m})$ & Sliding force $(\mathrm{kN})$ & Sliding resistance $(\mathrm{kN})$ & Distributed line load $(\mathrm{kN} / \mathrm{m})$ \\
\hline \multirow{2}{*}{1} & \multirow{2}{*}{$B C D$} & $B C$ & 4.717 & 21259.828 & 19479.445 & 377.440 \\
& & $C D$ & 5.002 & 20049.666 & 59.577 & 3996.419 \\
\hline \multirow{2}{*}{2} & \multirow{2}{*}{$F G H$} & $F G$ & 7.876 & 16255.554 & 14355.040 & 241.304 \\
& & $G H$ & 4.479 & 28583.578 & 60.637 & 6368.149 \\
\multirow{2}{*}{3} & \multirow{2}{*}{ JKL } & $K K$ & 9.708 & 20640.669 & 17914.429 & 280.824 \\
& & $K L$ & 5.562 & 35912.627 & 64.457 & 6445.194 \\
\hline \multirow{2}{*}{4} & \multirow{2}{*}{ KNO } & $K N$ & 11.208 & 17176.507 & 14598.502 & 230.015 \\
& & $N O$ & 10.457 & 39324.825 & 256.212 & 3736.121 \\
\hline
\end{tabular}

where $\sigma_{x}$ is the analytical calculation of the horizontal elastic resistance below the slip surfaces, $\sigma_{y}$ is the analytical calculation of the vertical elastic resistance below the slip surfaces, $q_{x}$ is the numerical calculation of the horizontal interaction between the antislide members and geotechnical materials, $q_{y}$ is the numerical calculation of the vertical interaction between the antislide members and geotechnical materials, $\mathrm{d} Q(x)$ is the horizontal shear force difference of the microelement on the antislide member, $\mathrm{dQ}(y)$ is the vertical shear force difference of the microelement on the antislide member, $\mathrm{d} x$ is the horizontal length of the microelement that is equal to $0.5 \mathrm{~m}$ on the antislide member by using numerical simulation software (MIDAS GTS NX), and $\mathrm{d} y$ is the vertical length of the microelement that is equal to $0.5 \mathrm{~m}$ on the antislide member by using numerical simulation software (MIDAS GTS NX).

\subsection{Comparative Analysis of the Structural Effects}

4.4.1. Comparative Analysis of the Displacement. Due to the small structural displacements, the initial location and displacements of the structures cannot be distinguished with the numerical simulation at the original scaling. Taking the shape of the ASCL as a benchmark, the analytical calculation and the numerical simulation of the displacements were enlarged at different scales. A comparative figure of the enlarged displacements is given in Figure 12. In Figure 12, the global displacements caused deformation toward downwards to the right, and the results of the analytical calculation of the structural displacements were similar to the distribution of the numerical results, showing that the ASCL was bearing the landslide thrust and the resistance of the geotechnical materials.

A comparative table of the structural displacements of the antislide members is given in Table 4 . In Table 4 and the following tables, $E$ was equal to 10 . In Table 4 , the structural displacement results of the analytical calculation and numerical simulation were different due to the different calculation methods and assumptions. When the structural mechanics and elastic foundation beam method were adopted to analytically calculate the structural displacements, the minor loads that included the gravity of the antislide members, friction, and end-bearing force between the antislide members and geotechnical materials were ignored, and the resulting structural displacements of the horizontal antislide members presented only vertical displacements, without horizontal displacements, while that of

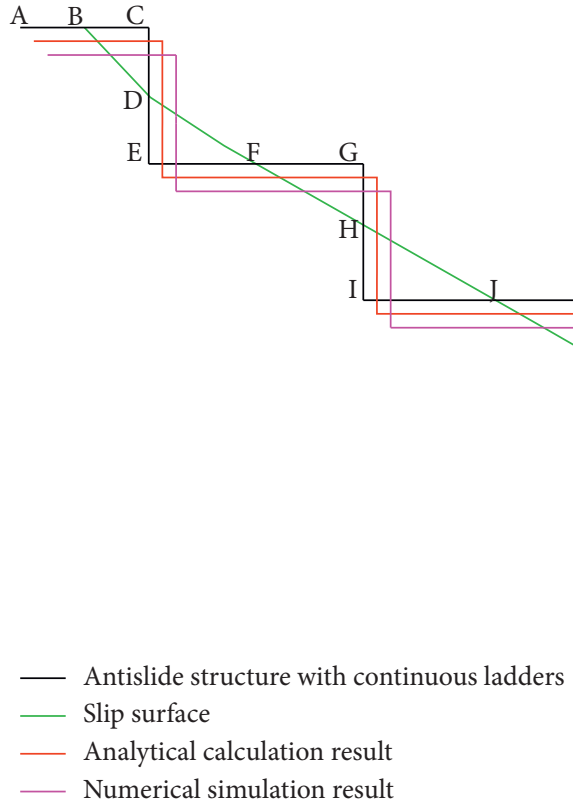

Figure 12: A comparative figure of the enlarged displacements. The black lines represent the initial shape of the ASCL, and the green lines represent the slip surface. Taking the initial shape of the ASCL as a standard, the red lines represent the displacements of the analytical calculations, while the pink lines represent the displacements of the numerical calculations.

the vertical antislide members presented only horizontal displacements, without vertical displacements. Otherwise, due to the minor loads that included the gravity of antislide members, the interaction between the antislide members and geotechnical materials, and the effects that were simulated as the intercoupling between the antislide members and geotechnical materials, the maximum numerically determined structural displacements were greater than the maximum analytically calculated structural displacements. The corresponding ratios of the maximum displacements of the global structures were equal to 0.820 for the horizontal displacement, 0.031 for the vertical displacement, and 4.342 for the angular displacement. Thus, the numerical simulation of the structural displacements was proposed to be adopted.

4.4.2. Comparative Analysis of the Axial Force. As mentioned before, the global displacements presented a 
TABle 4: A comparative table of the structural displacements of the antislide members.

\begin{tabular}{|c|c|c|c|c|c|c|c|c|c|}
\hline Member & $\begin{array}{c}\text { Maximum } \\
\text { analytical } \\
\text { calculation of } \\
\text { horizontal } \\
\text { displacement } \\
\text { Dx }(\mathrm{m})\end{array}$ & $\begin{array}{c}\text { Maximum } \\
\text { numerical } \\
\text { simulation of } \\
\text { horizontal } \\
\text { displacement } \\
\mathrm{Dx}^{\prime}(\mathrm{m})\end{array}$ & $\begin{array}{l}\mathrm{Dx} / \\
\mathrm{Dx}^{\prime}\end{array}$ & $\begin{array}{c}\text { Maximum } \\
\text { analytical } \\
\text { calculation of } \\
\text { vertical } \\
\text { displacement } \\
\text { Dy }(\mathrm{m})\end{array}$ & $\begin{array}{c}\text { Maximum } \\
\text { numerical } \\
\text { simulation of } \\
\text { vertical } \\
\text { displacement } \\
\mathrm{Dy}^{\prime}(\mathrm{m})\end{array}$ & $\begin{array}{l}\text { Dy/ } \\
\text { Dy }^{\prime}\end{array}$ & $\begin{array}{c}\text { Maximum } \\
\text { analytical } \\
\text { calculation of } \\
\text { angular } \\
\text { displacement } \\
\text { Dr (rad) }\end{array}$ & $\begin{array}{c}\text { Maximum } \\
\text { numerical } \\
\text { simulation of } \\
\text { angular } \\
\text { displacement } \\
\text { Dr' }(\mathrm{rad})\end{array}$ & $\begin{array}{l}\mathrm{Dr} / \\
\mathrm{Dr}^{\prime}\end{array}$ \\
\hline $\mathrm{AC}$ & 0 & $6.626 E-03$ & 0 & $-6.047 E-04$ & $-1.747 E-02$ & 0.035 & $1.795 E-04$ & $3.235 E-04$ & 0.555 \\
\hline $\mathrm{CE}$ & $2.270 E-03$ & $6.623 E-03$ & 0.343 & 0 & $-1.746 E-02$ & 0 & $7.741 E-04$ & $1.155 E-04$ & 6.702 \\
\hline EG & 0 & $5.914 E-03$ & 0 & $-4.737 E-04$ & $-1.758 E-02$ & 0.027 & $2.215 E-04$ & $1.607 E-04$ & 1.378 \\
\hline GI & $3.408 E-03$ & $6.026 E-03$ & 0.566 & 0 & $-1.679 E-02$ & 0 & $1.104 E-03$ & $1.194 E-04$ & 9.246 \\
\hline IN & 0 & $5.271 E-03$ & 0 & $-4.720 E-04$ & $-1.941 E-02$ & 0.024 & $2.564 E-04$ & $4.473 E-04$ & 0.573 \\
\hline KM & $4.162 E-03$ & $5.249 E-03$ & 0.793 & 0 & $-1.858 E-02$ & 0 & $1.216 E-03$ & $2.537 E-04$ & 4.793 \\
\hline NP & $5.431 E-03$ & $5.459 E-03$ & 0.995 & 0 & $-1.652 E-02$ & 0 & $1.942 E-03$ & $2.965 E-04$ & 6.550 \\
\hline Total & $5.431 E-03$ & $6.626 E-03$ & 0.820 & $-6.047 E-04$ & $-1.941 E-02$ & 0.031 & $1.942 E-03$ & $4.473 E-04$ & 4.342 \\
\hline
\end{tabular}

deformation downwards to the right, resulting in an apparent domino effect. This domino effect is shown in Figure 13, and a comparison of the axial forces of the ASCL is shown in Figure 14. According to Figures 13 and 14, the trend of the analytical calculation of the structural axial force was close to the trend of the numerical simulation of the structural axial force. The analytical calculation and numerical simulation of the axial force of the horizontal antislide member indicated mostly axial tension, while the analytical calculation and numerical simulation of the axial force of the vertical antislide members indicated mostly axial pressure, confirming that the global displacements reflected deformation downwards to the right. The horizontal antislide members acted as tie rods, while the vertical antislide members bearing the resultant force between the thrust and the sliding resistance presented deformation downwards to the right. Notably, the horizontal antislide members that were not strictly acting as tie rods bore the axial force, the shear force, and the bending moment.

A comparative table of the axial force of the antislide members is given in Table 5. In Table 5, the analytical calculation result of the axial force was different from the numerical simulation result of axial force due to the different calculation methods and assumptions. The ratio of the maximum axial forces of the global structures was equal to 10.755 , while the ratio of the minimum axial forces of the global structures was equal to 0.176 . Based on the principle of internal stress envelope diagrams, the maximum result from the analytical calculation of the axial force, which was equal to $33800.857 \mathrm{kN}$, and the minimum result from the numerical simulation of the axial force, which was equal to $-39304.948 \mathrm{kN}$, were proposed to be adopted.

4.4.3. Comparative Analysis of the Shear Force. A comparative figure of the shear force of the ASCL is shown in Figure 15. In Figure 15, the trend of the analytical calculation results of the structural shear force was close to the trend of the numerical simulation results of the structural shear force. The horizontal antislide members bore a positive shear force due to the vertical loads, while the top of the vertical antislide members bore a negative shear force due to the horizontal antislide members acting as tie rods. However, the negative

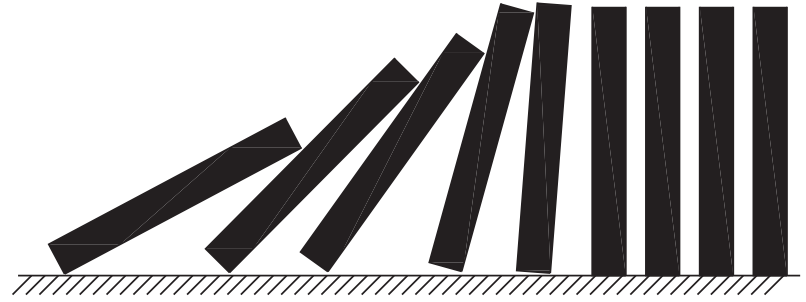

Figure 13: The domino effect. The domino effect occurs when several dominoes are arranged in rows according to certain spacing; when the first domino is pushed over, the other dominoes behind it will be pushed over in a chain reaction.

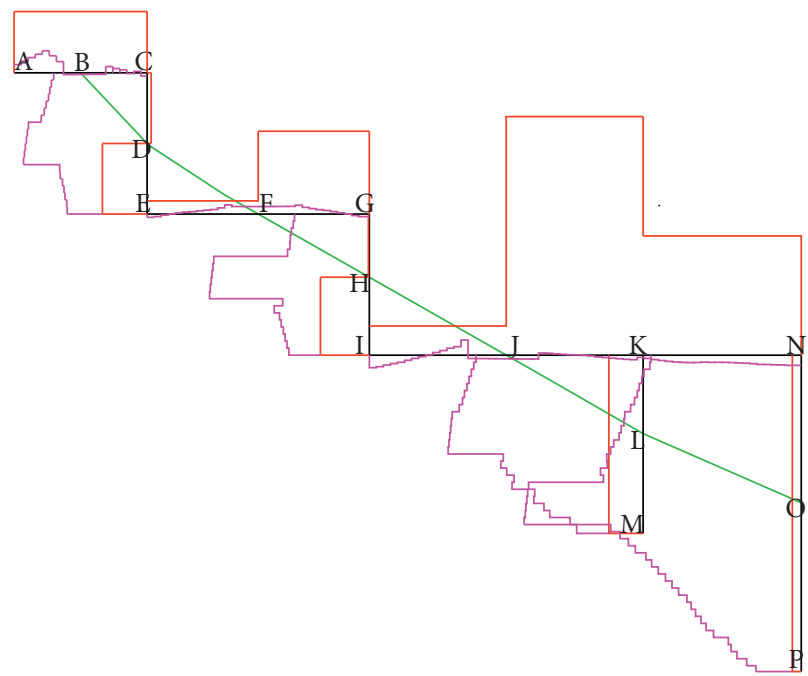

_ Antislide structure with continuous ladders

_ Slip surface

_ Analytical calculation result

_ Numerical simulation result

$-8000 \mathrm{kN}$

FIgURE 14: A comparison of the axial forces of the ASCL. The black lines represent the initial shape of the ASCL, and the green lines represent the slip surface. Taking the initial shape of the ASCL as a standard, the red lines represent the axial force of the analytical calculations, while the pink lines represent the axial force of the numerical calculations. 
TABLE 5: A comparative table of the axial force of the antislide members.

\begin{tabular}{|c|c|c|c|c|c|c|}
\hline Member & $\begin{array}{c}\text { Maximum analytical } \\
\text { calculation of axial force } \\
F_{N}(\mathrm{kN})\end{array}$ & $\begin{array}{c}\text { Maximum numerical } \\
\text { simulation of axial force } \\
F_{N}^{\prime}(\mathrm{kN})\end{array}$ & $F_{N} / F_{N}^{\prime}$ & $\begin{array}{c}\text { Minimum analytical } \\
\text { calculation of axial force } \\
F_{n}(\mathrm{kN})\end{array}$ & $\begin{array}{c}\text { Minimum numerical } \\
\text { simulation of axial force } \\
F_{n}^{\prime}(\mathrm{kN})\end{array}$ & $F_{n} / F_{n}^{\prime}$ \\
\hline AC & 8680.444 & 3142.764 & 2.762 & 8680.444 & -1160.419 & -7.480 \\
\hline CE & 588.064 & -11339.797 & -0.052 & -6338.100 & -17527.28 & 0.362 \\
\hline EG & 11722.341 & 1284.828 & 9.121 & 1859.380 & -463.996 & -4.007 \\
\hline GI & -129.082 & -10593.592 & 0.012 & -6931.905 & -22643.862 & 0.306 \\
\hline IN & 33800.857 & 2133.859 & 15.840 & 4134.072 & -1777.112 & -2.326 \\
\hline KM & -4862.311 & -9423.572 & 0.516 & -4862.311 & -27649.174 & 0.176 \\
\hline NP & 1256.725 & -6426.624 & -0.196 & 1256.725 & -39304.948 & -0.032 \\
\hline Total & 33800.857 & 3142.764 & 10.755 & -6931.905 & -39304.948 & 0.176 \\
\hline
\end{tabular}

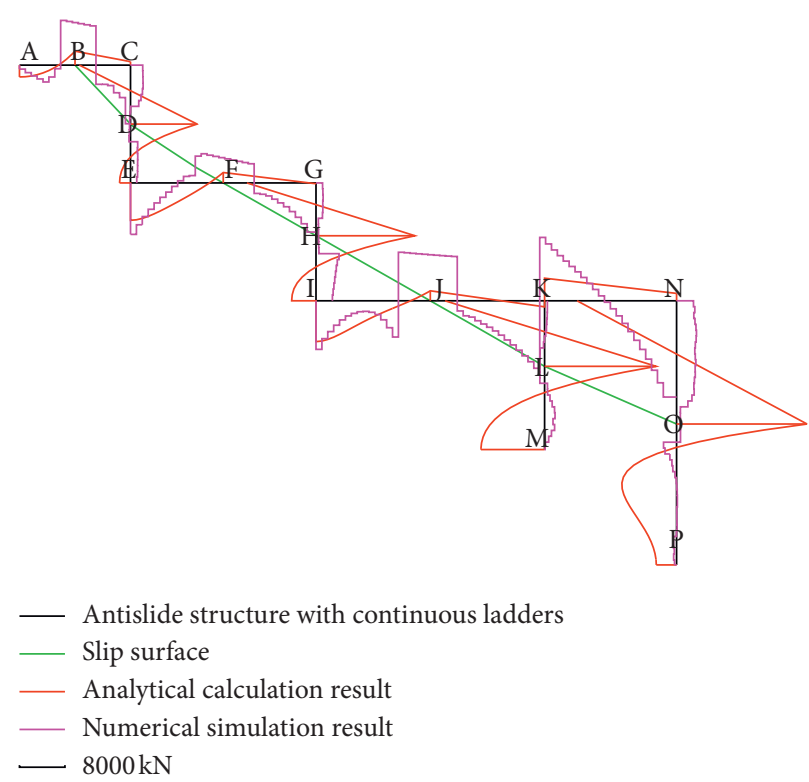

FIGURE 15: A comparative figure of the shear force of the ASCL. The black lines represent the initial shape of the ASCL, and the green lines represent the slip surface. Taking the initial shape of the ASCL as a standard, the red lines represent the shear force of the analytical calculations, while the pink lines represent the shear force of the numerical calculations.

shear force of the vertical antislide members decreased gradually and became a positive shear force because of the resultant force due to the thrust and the sliding resistance. Assuming that a slip surface is a boundary in the ASCL, the shear force of the members close to the slip surfaces was very high, and the shear force direction of the members above the slip surfaces and below the slip surfaces was opposite due to the interaction between the antislide members and geotechnical materials below the slip surfaces, which can decrease the shear force of the members above the slip surfaces.

A comparative table of the shear force of the antislide members is given in Table 6 . The analytical calculation result of the shear force was different from the numerical simulation result of the shear force due to the different calculation methods and assumptions. In Table 6, the ratio of the maximum shear forces of the global structures was equal to 2.061 , while the ratio of the minimum shear forces of the global structures was equal to 1.035 . The analytical calculation result of the structural shear force exhibited a hysteretic effect, unlike the numerical simulation result of the structural shear force, as the maximum result of the analytical calculation of the shear force was observed behind the members and the maximum result of the numerical simulation of the shear force was observed in the middle of the members. Based on the principle of internal stress envelope diagrams, the maximum shear force from the analytical calculation, which was equal to $22169.628 \mathrm{kN}$, and the minimum shear force from the analytical calculation, which was equal to $-16901.873 \mathrm{kN}$, were proposed to be adopted.

4.4.4. Comparative Analysis of the Bending Moment. The comparative figure of the bending moment of the ASCL is shown in Figure 16. In Figure 16, the direction of the analytical calculation result of the structural bending moment was contrary to the direction of the numerical simulation result of the structural bending moment at the top junction between the horizontal antislide members and the vertical antislide members due to the difference between the analytical calculation, which was a piecewise calculation, and the numerical simulation, which was a global calculation. The trend of the analytical calculation of the structural bending 
TABLE 6: A comparative table of the shear force of the antislide members.

\begin{tabular}{|c|c|c|c|c|c|c|}
\hline Member & $\begin{array}{c}\text { Maximum analytical } \\
\text { calculation of shear force } \\
F_{Q}(\mathrm{kN})\end{array}$ & $\begin{array}{c}\text { Maximum numerical } \\
\text { simulation of shear force } \\
F_{Q}^{\prime}(\mathrm{kN})\end{array}$ & $F_{Q} / F_{Q}^{\prime}$ & $\begin{array}{c}\text { Minimum analytical } \\
\text { calculation of shear force } \\
F_{q}(\mathrm{kN})\end{array}$ & $\begin{array}{c}\text { Minimum numerical } \\
\text { simulation of shear force } \\
F_{q}^{\prime}(\mathrm{kN})\end{array}$ & $F_{\mathrm{q}} / F_{q}^{\prime}$ \\
\hline$\overline{\mathrm{AC}}$ & 2368.447 & 7591.186 & 0.312 & -2010.671 & -9953.184 & 0.202 \\
\hline $\mathrm{CE}$ & 11309.645 & 2135.793 & 5.295 & -8680.444 & -255.003 & 34.041 \\
\hline EG & 1771.432 & 4952.278 & 0.358 & -6338.100 & -8730.515 & 0.726 \\
\hline GI & 16800.601 & 3912.311 & 4.294 & -11722.341 & 391.741 & -29.924 \\
\hline IN & 3834.730 & 10757.662 & 0.356 & -6931.905 & -16337.665 & 0.424 \\
\hline KM & 18946.297 & 1770.996 & 10.698 & -16901.873 & -809.663 & 20.875 \\
\hline NP & 22169.628 & 3380.761 & 6.558 & -16898.984 & -2215.348 & 7.628 \\
\hline Total & 22169.628 & 10757.662 & 2.061 & -16901.873 & -16337.665 & 1.035 \\
\hline
\end{tabular}
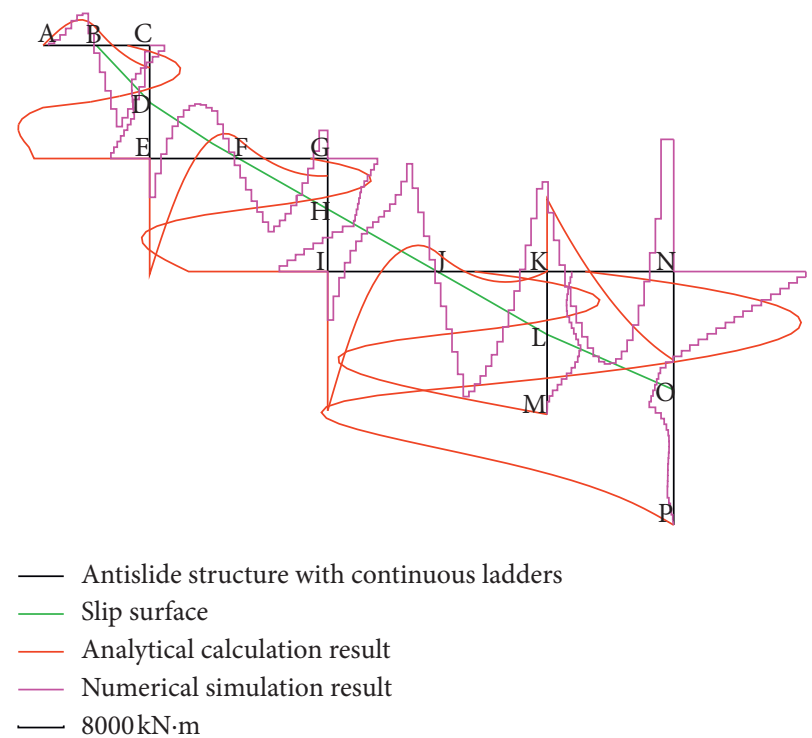

FIgURE 16: The comparative figure of the bending moment of the ASCL. The black lines represent the initial shape of the ASCL, and the green lines represent the slip surface. Taking the initial shape of the ASCL as a standard, the red lines represent the bending moment of the analytical calculations, while the pink lines represent the bending moment of the numerical calculations.

moment approached the trend of the numerical simulation of the structural bending moment, while the location of the member section gradually moved to the bottom joints of the vertical antislide members from the top joints between the horizontal antislide members and the vertical antislide members. Assuming that a slip surface is a boundary in the ASCL, the bending moments near the slip surfaces were larger. The top outer edges and the bottom outer edges of the horizontal antislide members and the vertical antislide members easily exhibited tensile bending moments due to the global displacements that resulted in the apparent domino effect; however, the bending moment reversed due to the interaction between the antislide members and geotechnical materials.

A comparative table of the bending moments of the antislide members is shown in Table 7. In Table 7, the ratio of the maximum bending moments of the global structures was equal to 0.964 , while the ratio of the minimum bending moments of the global structures was equal to 2.821 . For the same reason, the analytical calculation result of the structural bending moment exhibited a hysteretic effect, unlike the numerical simulation result of the structural bending moment. Based on the principle of internal stress envelope diagrams, the maximum bending moment from the numerical simulation, which was $23385.630 \mathrm{kN} \cdot \mathrm{m}$, and the minimum bending moment from the analytical calculation, which was appropriately decreased to $-36901.790 \mathrm{kN} \cdot \mathrm{m}$, were proposed to be adopted.

4.4.5. Comparative Analysis of the Interaction between the Members and Geotechnical Materials. A comparative figure of the interaction between the antislide members and geotechnical materials is shown in Figure 17. In Figure 17, the trend of analytical calculation result of the interaction between the antislide members and geotechnical materials approached the trend of the numerical simulation result of the interaction between the antislide members and geotechnical materials. Assuming that a slip surface is a boundary in the ASCL, the interaction between the antislide members and geotechnical materials on the slip surfaces was greater, the horizontal antislide members above the slip surfaces bare the downward load, while the vertical antislide members above the slip surfaces bare the rightward load. 
TABLE 7: A comparative table of the bending moments of the antislide members.

\begin{tabular}{lccccc}
\hline Member & $\begin{array}{c}\text { Maximum analytical } \\
\text { calculation of bending } \\
\text { moment } M(\mathrm{kN} \cdot \mathrm{m})\end{array}$ & $\begin{array}{c}\text { Maximum numerical } \\
\text { simulation of bending } \\
\text { moment } M^{\prime}(\mathrm{kN} \cdot \mathrm{m})\end{array}$ & $\begin{array}{c}M / \\
M^{\prime}\end{array}$ & $\begin{array}{c}\text { Minimum analytical } \\
\text { calculation of bending } \\
\text { moment } m(\mathrm{kN} \cdot \mathrm{m})\end{array}$ & $\begin{array}{c}\text { Minimum numerical } \\
\text { simulation of bending } \\
\text { moment } m^{\prime}(\mathrm{kN} \cdot \mathrm{m})\end{array}$ \\
\hline AC & 4521.471 & 5658.911 & 0.799 & -3948.781 & -14354.360 \\
CE & 5419.269 & 2605.432 & 2.080 & -23265.751 & -6865.637 \\
EG & 4388.188 & 9634.892 & 0.455 & -20468.400 & -12945.602 \\
GI & 7644.037 & 8805.704 & 0.868 & -32908.479 & -8560.654 \\
IN & 12859.184 & 23385.630 & 0.550 & -24614.286 & -22101.542 \\
KM & 9288.186 & 5922.715 & 1.568 & -36901.790 & 0 \\
NP & 22543.877 & 23385.630 & 0.964 & -62354.262 & -4.844 \\
Total & 22543.877 & 23385.630 & 0.964 & -62354.262 & $+\infty$ \\
\hline
\end{tabular}

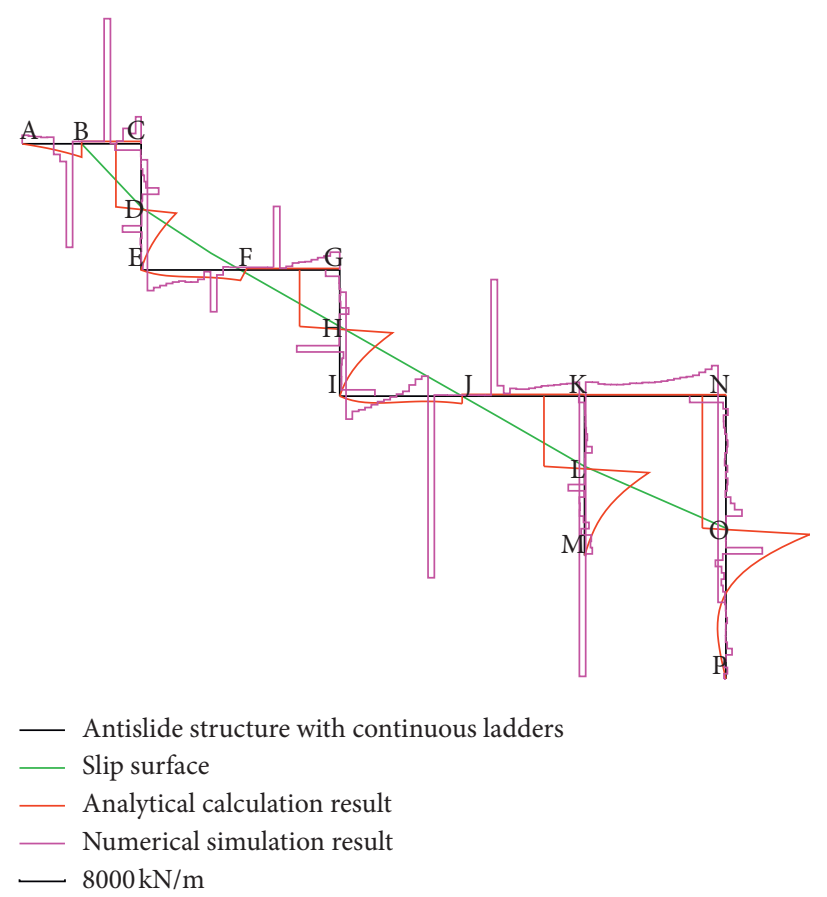

Figure 17: A comparative figure of the interaction between the antislide members and geotechnical materials. The black lines represent the initial shape of the ASCL, and the green lines represent the slip surface. Taking the initial shape of the ASCL as a standard, the red lines represent the interaction between the antislide members and geotechnical materials of the analytical calculations, while the pink lines represent the interaction between the antislide members and geotechnical materials of the numerical calculations.

TABLE 8: A comparative table of the interaction between the antislide members and geotechnical materials.

\begin{tabular}{|c|c|c|c|c|c|c|}
\hline Member & $\begin{array}{c}\text { Maximum analytical } \\
\text { calculation of interaction } \\
Q(\mathrm{kN} / \mathrm{m})\end{array}$ & $\begin{array}{c}\text { Maximum numerical } \\
\text { simulation of interaction } \\
Q^{\prime}(\mathrm{kN} / \mathrm{m})\end{array}$ & $Q / Q^{\prime}$ & $\begin{array}{c}\text { Minimum analytical } \\
\text { calculation of interaction } q \\
(\mathrm{kN} / \mathrm{m})\end{array}$ & $\begin{array}{c}\text { Minimum numerical } \\
\text { simulation of interaction } q^{\prime} \\
(\mathrm{kN} / \mathrm{m})\end{array}$ & $q / q^{\prime}$ \\
\hline$\overline{\mathrm{AC}}$ & 2116.450 & 19906.400 & 0.106 & -377.440 & -19826.880 & 0.019 \\
\hline $\mathrm{CE}$ & 3996.419 & 4144.950 & 0.964 & -5561.500 & -2786.002 & 1.996 \\
\hline EG & 1657.950 & 6617.800 & 0.251 & -241.304 & -17461.030 & 0.014 \\
\hline GI & 6368.149 & 6823.890 & 0.933 & -8349.600 & -5572.640 & 1.498 \\
\hline IN & 1185.100 & 44410.500 & 0.027 & -280.824 & -18480.410 & 0.015 \\
\hline KM & 6445.194 & 2584.850 & 2.493 & -10196.900 & -1224.288 & 8.329 \\
\hline NP & 3736.121 & 5745.290 & 0.650 & -13305.950 & -5764.500 & 2.308 \\
\hline Total & 6445.194 & 44410.500 & 0.145 & -13305.950 & -19826.880 & 0.671 \\
\hline
\end{tabular}


However, the interaction below the slip surfaces was reversed and decreased gradually due to the anchoring effects between the antislide members below the slip surfaces and the geotechnical materials on the slip bed.

A comparative table of the interaction between the antislide members and geotechnical materials is shown in Table 8. In Table 8, the maximum numerical simulation of the interaction between the antislide members and geotechnical materials was equal to $44410.500 \mathrm{kN} / \mathrm{m}$, so larger values were unreliable and should be eliminated if there was no approximate numerical simulation result provided nearby. Based on the principle of internal stress envelope diagrams, the maximum interaction between the antislide members and geotechnical materials from the numerical simulation, which was equal to $19906.4 \mathrm{kN} / \mathrm{m}$, and the minimum interaction between the antislide members and geotechnical materials from the numerical simulation, which was equal to $-19826.88 \mathrm{kN} / \mathrm{m}$, were proposed to be adopted.

\section{Conclusions and Future Work}

To verify the effect of antislide structures with continuous ladders on the slope stability, a new analytical method (the new stress calculation methods of antislide structures with continuous ladders that are based on the displacement method of structural mechanics and elastic foundation beam method) has been proposed. By researching the results of analytical methods and numerical simulation methods, the conclusions and future work are concluded as follows.

The trends of the displacements, axial force, shear force, bending moment, and interaction between the antislide members and geotechnical materials from the analytical calculations approached the corresponding trends from the numerical simulations. The results were different between the analytical calculations and the numerical simulations due to the different calculation methods and assumptions. However, by eliminating some unreliable values, the ultimate values from the analytical calculation results (shear force, bending moment, and interaction between the antislide members and geotechnical materials) were close to the ultimate values from the numerical simulation results, and these effects were greater on the slip surfaces than on the surrounding areas. The ultimate analytical result exhibited a hysteretic effect, unlike the ultimate numerical simulation result because the analytical calculation of structural stress was a piecewise calculation while the numerical simulation of structural stress considered a global calculation; this phenomenon was understood as the hysteretic effect of the analytical calculation due to a larger domino spacing relative to the numerical simulation. Based on the principle of internal stress envelope diagrams, the maximum absolute values of the analytical calculation results and numerical simulation results were proposed to be adopted, and the other values were proposed to a reference for the structural stress.

Research on the internal materials of the ASCLs (reinforced concrete, prestressed concrete, steel reinforced concrete, compound materials, etc.), seismic calculation of the ASCLs, physical simulation test of the ASCLs (jack loading test, large shake table test, centrifugal model test, etc.), structural stress calculation of the ASCLs under the multiple loads, structural reliability, etc., should be performed. Furthermore, the research findings of ASCLs, as they are further developed and improved, should be applied in practical engineering applications.

\section{Data Availability}

The data used to support the findings of this study are included within the article.

\section{Conflicts of Interest}

The authors declare that there are no conflicts of interest regarding the publication of this paper.

\section{Acknowledgments}

This research was supported by the Natural Science Foundation of Education Department of Sichuan Province (Grant no. 17ZB0013) and the Natural Science Foundation of Chengdu Textile College (Grant no. 2015fzlkc06).

\section{References}

[1] X. Zheng, "Research on reinforcement \& anti-slide mechanism and key technologies of engineering application of continuous pile-plug structure," Institute of Rock and Soil Mechanics, Chinese Academy of Sciences, Wuhan, China, 2010.

[2] X. Zheng and L. W. Kong, "Research on anti-slide mechanism and reinforcement effects of continuous pile-plug structure," Rock and Soil Mechanics, vol. 35, no. 9, pp. 2616-2622, 2014.

[3] C. L. Zou, X. Zheng, C. Y. Xiong, and L. Z. Zhu, "Design of control works for Houzishi landslide in three Gorges area," Yangtze River, vol. 39, no. 6, pp. 57-61, 2008.

[4] J. Fu, X. L. Ding, C. L. Zou, and X. Zheng, "Application of Lagrangian difference method based on shear strength reduction," Journal of Yangtze River Scientific Research Institute, vol. 25, no. 2, pp. 58-79, 2008.

[5] X. K. Ma, "Study on treatment project and antiskid key of sanmashan landslide," Southwest Jiaotong University, Chengdu, China, 2008.

[6] T. Ito and T. Matsui, "Methods to estimate lateral force acting on stabilizing piles," Soils and Foundations, vol. 15, no. 4, pp. 43-59, 1975.

[7] S. S. Rajashree and R. Sundaravadivelu, "Degradation model for one-way cyclic lateral load on piles in soft clay," Computers and Geotechnics, vol. 19, no. 4, pp. 289-300, 1996.

[8] U. B. Halabe and S. K. Jain, "Lateral free vibration of a single pile with or without an axial load," Journal of Sound and Vibration, vol. 195, no. 3, pp. 531-544, 1996.

[9] S. Hassiotis, J. L. Chameau, and M. Gunaratne, "Design method for stabilization of slopes with piles," Journal of Geotechnical and Geoenvironmental Engineering, vol. 123, no. 4, pp. 314-323, 1997.

[10] J. M. Abbas, Z. H. Chik, and M. R. Taha, "Single pile simulation and analysis subjected to lateral load," Electronic Journal of Geotechnical Engineering, vol. 13, pp. 1-15, 2008. 
[11] R. Frank and P. Pouget, "Experimental pile subjected to long duration thrusts owing to a moving slope," Géotechnique, vol. 58, no. 8, pp. 645-658, 2008.

[12] R. Kourkoulis, F. Gelagoti, I. Anastasopoulos, and G. Gazetas, "Slope stabilizing piles and pile-groups: parametric study and design insights," Journal of Geotechnical and Geoenvironmental Engineering, vol. 137, no. 7, pp. 663-677, 2011.

[13] T. K. Nian, H. Y. Xu, and H. S. Liu, "Several issues in threedimensional numerical analysis of slopes reinforced with antislide piles," Rock and Soil Mechanics, vol. 33, no. 8, pp. 2521-2535, 2012.

[14] S. Lirer, "Landslide stabilizing piles: experimental evidences and numerical interpretation," Engineering Geology, vol. 149150, pp. 70-77, 2012.

[15] M. Ashour and H. Ardalan, "Analysis of pile stabilized slopes based on soil-pile interaction," Computers and Geotechnics, vol. 39, pp. 85-97, 2012.

[16] I. Shooshpasha and H. A. Amirdehi, "Evaluating the stability of slope reinforced with one row of free head piles," Arabian Journal of Geosciences, vol. 8, no. 4, pp. 2131-2141, 2015.

[17] F. S. Tehrani, M. Prezzi, and R. Salgado, "A multidirectional semi-analytical method for analysis of laterally loaded pile groups in multi-layered elastic strata," International Journal for Numerical and Analytical Methods in Geomechanics, vol. 40, no. 12, pp. 1730-1757, 2016.

[18] M. R. Kahyaoglu, G. Imançh, G. Ozden, and A. Ş. Kayalar, "Numerical simulations of landslide stabilizing piles: a remediation project in Soke, Turkey," Environmental Earth Sciences, vol. 76, no. 19, p. 656, 2017.

[19] A. Vega-Posada Carlos, P. Gallant Aaron, and M. AreizaHurtado, "Simple approach for analysis of beam-column elements on homogeneous and non-homogeneous elastic soil," Engineering Structures, vol. 221, Article ID 111110, 2020.

[20] K. Aqoub, M. Mohamed, and T. Sheehan, "Quantitative analysis of shallow unreinforced and reinforced piled embankments with different heights subject to cyclic loads: experimental study," Soil Dynamics and Earthquake Engineering, vol. 138, p. 106277, 2020.

[21] P. A. Belato, P. T. Bomjardim, G. R. César, R. L. R. d. Santos, and R. J. M. Guimarães, "Forecasting bearing capacity performance with semi-empirical and theoretical methods applied to precast concrete piles founded on sandy clay in the region of Uberlândia-MG, Brazil," REM-International Engineering Journal, vol. 73, no. 4, pp. 463-475, 2020.

[22] S. A. Pratap and K. Chatterjee, "Lateral earth pressure and bending moment on sheet pile walls due to uniform surcharge," Geomechanics and Engineering, vol. 23, no. 1, pp. 71-83, 2020.

[23] Y. Naphol, J. Pitthaya, K. Krissakorn, J. Pornkasem, and L. Suched, "Laboratory investigation of the properties of cement fly ash gravel for use as a column-supported embankment," Construction and Building Materials, vol. 257, p. 119493, 2020.

[24] M. Y. Fattah, R. R. Al-Omari, and S. H. Fadhil, "Load sharing and behavior of single pile embedded in unsaturated swelling soil," European Journal of Environmental and Civil Engineering, vol. 24, no. 12, pp. 1967-1992, 2020.

[25] V. Amir, Z. S. M. Ali, and T. Arash, "Laboratory and threedimensional numerical modeling of laterally loaded pile groups in sandy soils," Iranian Journal of Science and Technology-Transactions of Civil Engineering, 2020, In press.

[26] Chongqing Construction Committee and Chongqing Administration of Land and Resources and Housing, "Code for design of geohazard prevention engineering," no. DB 50/ 5029-2004, Chongqing, China, 2004.

[27] Ministry of Land and Resources of the People's Republic of China, "Specification of design and construction for landslide stabilization," China Standard Press, Beijing, China, no. DZ/T 0219-2006, 2006.

[28] National Development and Reform Commission of the People's Republic of China, "Design code for engineered slopes in hydropower projects and water resources," China Water Power Press, Beijing, China, no. DL/T 5353-2006, 2006.

[29] Ministry of Water Resources of the People's Republic of China, "Design code for engineered slopes in water resources and hydropower projects," China WaterPower Press, Beijing, China, no. SL 386-2007, 2007.

[30] H. G. Li, Structural Design and Engineering Cases of the New Retaining Structure, China Communications Press, Beijing, China, 2004.

[31] Ministry of Railways of the People's Republic of China, "Code for design on retaining structures of railway subgrade," China Railway Publishing House, Beijing, China, no. TB 100252006, 2009.

[32] Y. R. Zheng, W. M. Shi, and M. C. Yang, "Discussion on imbalance thrust force method and sarma's method," Chinese Journal of Rock Mechanics and Engineering, vol. 23, no. 17, pp. 3030-3036, 2004

[33] Y. R. Zheng, Z. Y. Chen, G. X. Wang, and T. Q. Ling, Engineering Treatment of Slope and Landslide, China Communications Press, Beijing, China, 2007.

[34] The 2rd Survey and Design Institute of the Ministry of Railways, Design and Calculation of Anti-slide Piles, China Railway Publishing House, Beijing, China, 1983. 